Revista Ibero-Americana de Ciências Ambientais

Ibero-American Journal of Environmental Sciences

Dossiê Especial do Mestrado de Ciências Ambientais da Universidade do Estado de Mato Grosso - Jan 2018 - v.9 - n.1

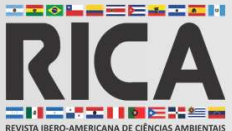

ISSN: 2179-6858

\title{
Produtos naturais anti - Helicobacter pylori: revisão
}

A infecção pela bactéria Helicobacter pylori é considerada um problema de saúde pública, com intrínseca relação saúde e ambiente, a infecção bacteriana crônica mais comum no mundo, com alta prevalência em países em desenvolvimento. $O$ uso de produtos naturais voltados a inovação medicamentosa, aumenta o interesse por novos princípios ativos a base de produtos naturais, contudo, a atividade antibacteriana forte ainda é controversa quanto a concentração inibitória mínima desses produtos, principalmente no que tage à $\mathrm{H}$. pylori. Este trabalho realizou uma revisão sistemática dos produtos naturais com atividades anti-Helicobacter pylori disponíveis na literatura tendo como parâmetro inicial a revisão de plantas medicinais anti-H. pylori analisadas por Wang (2014) e como critério de classificação a concentração inibitória mínima. A pesquisa foi desenvolvida por meio da busca de artigos nas bases de dados online BVS, BDENF, analisadas por Wang (2014) e como critério de classificação a concentração inibitória mínima. A pesquisa foi desenvolvida por meio da busca de artigos nas bases de dados online BVS, BDENF,
LILACS, MEDLINE, PUBMED, Scielo, Bireme e ScienceDirect., os descritores utilizados foram: Helicobacter pylori, anti-Helicobacter pylori, produtos naturais, atividade antibacteriana, própolis e mel, traduzidos para o inglês. A busca resultou no total de 138 artigos, dos quais 59 artigos são da revisão de Wang (2014) e outros 79 foram encontrados nas bases de dados, que proporcionou um acréscimo de 57 artigos de plantas medicinas, 12 artigos de produtos distintos de plantas medicinais (mel, própolis, iogurte e cogumelo) e 10 artigos de estudos clínicos e in vivo. Foram encontrados 162 produtos naturais distintos, a maioria deles plantas medicinais, resultando na avaliação de 128 produtos naturais anti-Helicobacter pylori. Segundo a classificação de Wang somente 16 produtos apresentam atividade forte, e a maioria deles são frações. Com atividade forte-moderada mostra 45 produtos; com atividades moderada-fraca e fraca mostram 37 e 30 produtos, respectivamente. A nova classificação de produtos naturais com atividade anti-H. pylori proposta nessa pesquisa apresenta 5 classes de acordo com a sua concentra 0 in forte, com 19 fraç̃̃es e 24 extratos; 40 produtos com atividade boa; 18 com atividades moderada e 15 produtos com fraca; na classificação sem atividade quatro produtos. A revisão ampliou os produtos naturais anti- Helicobacter pylori com novas plantas medicinais, produtos de origem animal e estudos clínicos e pré-clínicos. A nova classificação permitiu a inclusão de outros extratos vegetais, produtos de origem animal e fungos com atividade anti-Helicobacter pylori, e ampliou a faixa de produtos considerados com forte atividade.

Palavras-chave: Helicobacter pylori; Produtos Naturais; Atividade Antibacteriana; Mel; Própolis

\section{Anti natural products - Helicobacter pylori: review}

Helicobacter. pylori infection is the most common chronic bacterial infection in the world, with an intrinsic relationship between health and the environment factors and it is considered global public health problem, it has a high prevalence in developing countries. The use of natural products aimed at drug innovation increases the interest for new active principles based on natural products, however, the strong antibacterial activity is still controversial as to the minimum inhibitory concentration of these products, mainly in relation to $\mathrm{H}$. pylori. However, the classification of the antibacterial activity is still controversial regarding the minimum inhibitory concentration, mainly in relation to $\mathrm{H}$. pylori. This work carried out a systematic review of the natural products that have anti-Helicobacter pylori activity, using the Wang (2012) review about anti-H. pylori medicinal plants as a starting point, considering the minimum inhibitory concentration as the classifiction criterion. The search was mad in Helicobacter pylori, anti-Helicobacter pylori, nat and other 79 were found in the databases, which provided an increase of 57 articles of medicinal plants, 12 articles of products other than medicinal plants (honey, propolis, yogurt and and other 79 were found in the databases, which provided an increase of 57 articles of medicinal plants, 12 articles of products other than medicinal plants (honey, propolis, yogurt and
mushroom) and 10 articles from clinical and in vivo studies. 162 distinct natural products were found, most of them medicinal plants, in 128 articles. According to Wang's classification, only 16 of these natural products show strong activity, and most of them are fractions; 45 show strong-moderate activity, 37 moderate-weak and 30 weak activities. The new classification of natural products with anti-H. pylori activity proposed in this research presents 5 classes according to their minimum inhibitory concentration: products with strong, good, moderate, weak and no activity. According to this new classification, 43 natural products were classified as strong activity, which 19 are fractions and 24 are extracts, 40 products were classified as good activity, 18 moderate , 15 weak activity, and only 4 products as no activity. This review extended the classifications natural anti-Helicobacter pylori products by inclusion of new medicina plants, animal products and clinical and preclinical studies. The new classification allowed the inclusion of other plant extracts, animal products and fungi with anti-Helicobacter pylori activity, and expanded the range of products considered with strong activity.

Keywords: Helicobacter pylori; Natural Products; Antibacterial Activity; Honey; Propolis.

Topic: Epidemiologia e Saúde Ambiental

Reviewed anonymously in the process of blind peer.
Received: 02/02/2018

Approved: 20/05/2018

Mariana Lenina Menezes Aleixo (iD)

Universidade do Estado do Mato Grosso, Brasil

http://lattes.cnpq.br/2641517259797926

http://orcid.org/0000-0002-9363-2423

marianaaleixo@uol.com.br

Carla Galbiati (D)

Universidade do Estado de Mato Grosso, Brasil http://lattes.cnpq.br/4449909695203792 http://orcid.org/0000-0001-5442-1562

carla@unemat.br

Larissa Maria Scalon Lemos (iD

Universidade do Estado de Mato Grosso, Brasil http://lattes.cnpq.br/9276020258429877 http://orcid.org/0000-0009-5500-6326

Imscalon@hotmail.com

\section{Referencing this:}

ALEIXO, M. L. M.; GALBIATI, C.; LEMOS, L. M. S.. Produtos naturais anti - Helicobacter pylori: revisão. Revista Ibero-Americana de Ciências Ambientais, v.9, n.1, p.56-72, 2018. DOI: 


\section{INTRODUÇÃO}

O número de estudos sobre a bactéria Helicobacter pylori aumentou exponencialmente nos últimos 25 anos, são aproximadamente cerca de 10.000 estudos de 1994 a 2018 que versam sobre o desenvolvimento da bactéria, cultivo, diagnóstico, patologias relacionadas à infecção e tratamento. Estimase que metade da população mundial é portadora da Helicobacter pylori, embora apenas $10 \%$ dessa população desenvolve problemas clínicos relacionadas e H. pylori, o ônus das patologias causadas pela essa bactéria é enorme e sua eliminação traz um grande impacto na saúde mundial (TEIXEIRA et al., 2017).

Atualmente, o tratamento da infecção por Helicobacter pylori consiste no uso combinado de dois antibióticos (claritromicina e amoxicilina ou metronidazol) e um inibidor de bomba de prótons, de acordo com as diretrizes definidas pelo V Consenso de Maastricht e American College of Gastroenterology Guideline on the Management of Helicobacter pylori Infection (MALFERTHEINER et al., 2016). Essa terapia não atinge as taxas de cura desejáveis e o relatório do Consenso não recomenda o uso da claritromicina em regiões com alta prevalência de resistência à claritromicina (MALFERTHEINER et al., 2016). Portanto, sua erradicação com terapias medicamentosas tem várias limitações, principalmente devido à resistência aos antibióticos, fato que aponta a necessidade da busca de novas terapias.

Produto natural é aquele produzido pela "natureza" ou conforme as "leis da natureza", com a menor interferência humana possível, ou advindos diretamente de partes de vegetais ou de animais. Normalmente associa-se à produção artesanal ou não-industrial (GOMES 2009). Contudo, esse conceito ainda é bastante controverso. A Organização Mundial da Saúde reconhece a importância dos produtos naturais no desenvolvimento de modernas drogas terapêuticas, com importância para a pesquisa farmacológica, não somente quando os constituintes usados diretamente como agentes terapêuticos, mas também como matérias-primas para a síntese, ou modelos para compostos farmacologicamente ativos (WHO, 1998).

Um produto com potencial antibacteriano deve ter a capacidade de inibir o crescimento bacteriano, e a classificação dessa atividade é um critério importante na seleção desses produtos, mas ainda há muitas divergências dos autores quanto a esses critérios de classificação. Alguns autores consideram com atividade antimicrobiana forte, os extratos vegetais com concentração inibitória mínima (CIM) menor que $100 \mu \mathrm{g} / \mathrm{mL}$ (Holetz et al., 2012), para óleos essenciais até $500 \mu \mathrm{g} / \mathrm{mL}$ (Aligiannis et al., 2001), entre outros. Essa diferença entre os critérios de classificação da atividade antibacteriana continua para a atividade fraca, Castillo-Juarez et al., (2009) e Holetz et al., (2012) consideraram produtos com CIM até $1000 \mu \mathrm{g} / \mathrm{mL}$ com atividade fraca, já Fabry et al. (1998) considerou extratos com concentrações menores que $8000 \mu \mathrm{g} / \mathrm{mL}$ com atividade antibacteriana aproveitável. No entanto, nenhum desses critérios são específicos para a atividade antiHelicobacter pylori.

Uma classificação de plantas medicinais anti-Helicobacter pylori foi realizada por Wang (2014), que usou quatro classes de acordo com a sua concentração inibitória mínima, atividade forte (CIM $<10 \mu \mathrm{g} / \mathrm{mL}$ ), atividade forte-moderada (CIM $10-100 \mu \mathrm{g} / \mathrm{mL}$ ), atividade fraca-moderada (CIM $100-1000 \mu \mathrm{g} / \mathrm{mL}$ ) e atividade fraca (CIM: > $1000 \mu \mathrm{g} / \mathrm{mL}$ ). Essa classificação foi mais restritiva que a de Holetz et al., (2012), 
Aligiannis et al., (2001) e Fabry et al. (1998), além de só incluir produtos naturais provenientes de plantas medicinais logo, seria interessante ampliar a lista de produtos naturais com atividade anti-Helicobacter pylori.

A literatura mostra que vários produtos naturais de origem vegetal apresentaram promissora inibição das infecções por H. pylori, como alho, vinho, uva, pimenta e óleos essenciais (NJUME et al., 2011; PARK et al., 2006; HAMASAKI et al., 2000; INATSU et al., 2006), além de outros de origem animal como mel e própolis (KIM et al., 2017; AJIBOLA et al., 2012; VIUDA-MARTOS et al., 2008). No Brasil, estudos com produtos naturais com atividade anti-H. pylori ainda são escassos, contudo as plantas medicinais Leonotis Nepetifolia e Calophyllum brasiliense apresentaram resultados promissores (Do Carmo Souza et al., 2009; Oliveira et al., 2015; Lemos et al., 2016), assim como a própolis brasileira (Regueira Neto et al., 2017 e Banskota et al., 2001) e o mel do bioma Amazônia de Mato Grosso (Franz, 2015) para inibição do crescimento bacteriano."

Em razão da falta de consenso nos critérios de classificação dos produtos naturais com atividade antimicrobiana, e em especial, para atividade anti-H. pylori, foi realizada uma revisão sistemática da literatura com o objetivo de levantar os produtos naturais anti-Helicobacter pylori já estudados, suas respectivas concentrações inibitórias mínimas, com vistas à proposição de uma classificação, tendo como base as plantas medicinais analisadas por Wang (2014).

\section{METODOLOGIA}

Trata-se de um estudo de revisão sistemática, conduzida conforme a metodologia adaptada Preferred Reporting Items for Systematic Reviews and Meta-Analyses - PRISMA (MOHER et al., 2009). A busca de artigos sobre produtos naturais anti-Helicobacter pylori foi realizada nas bases de dados online BVS (Biblioteca virtual de Saúde), que integra as bases de dados BDENF (Base de dados de enfermagem), LILACS (Literatura Latino-Americana e do Caribe em Ciências da Saúde), MEDLINE (Literatura Internacional em Ciências da Saúde), PUBMED (Medical Literatura Analysis and Retrieval System Online), Scielo, Bireme e ScienceDirect. Ao resultado dessa busca ainda foi integrado os artigos de produtos naturais provenientes da revisão de Wang (2014), utilizando os mesmos critérios de elegibilidade bases de dados.

Os descritores utilizados na base de dados como termos de busca foram: Helicobacter pylori, produtos naturais, atividade antibacteriana, mel e própolis, todos os termos foram traduzidos para inglês: "Helicobacter pylori", "natural products", "antibacterial activity", "honey" e "propolis". Em todas as buscas foi utilizado o nome da bactéria seguido do outro termo de busca, por exemplo: "Helicobacter pylori" and "natural products".

Como critérios de inclusão dos artigos para análise verificamos se a atividade antibacteriana foi avaliada por meio da concentração inibitória mínima (CIM), tipo e obtenção do produto (extração e/ou fracionamento), cepa bacteriana, dose em estudos in vivo e estudos clínicos. Com base nesses critérios, foram excluídos os artigos que abordavam constituintes químicos dos produtos sem demonstrar o potencial antibacteriano, compostos sintéticos, substâncias isoladas, outras metodologias para a avaliação da 
atividade antibacteriana diferente da concentração inibitória mínima ou dose, uso empírico, artigos de revisão e estudos em idiomas chinês, japonês, francês, polonês, russo e húngaro foram excluídos.

A análise qualitativa dos artigos coletados foi realizada em três etapas. Inicialmente foram lidos todos os títulos dos artigos encontrados nas bases de dados com os descritores utilizados. A segunda etapa, constitui-se na análise dos resumos para constatar a definição de concentração inibitória mínima ou dose do produto natural. Na terceira e última etapa, os artigos selecionados foram analisados integralmente, de acordo com os critérios de elegibilidade a fim de verificar o potencial bacteriano do produto.

A sensibilidade dos microrganismos aos antimicrobianos é representada pela concentração inibitória mínima (CIM) de cada microrganismo para cada antimicrobiano, que corresponde à menor concentração do antimicrobiano capaz de inibir o desenvolvimento visível do microrganismo (ANVISA 2007).

Para a classificação dos produtos naturais encontrados na revisão realizada nesse trabalho usou-se o critério proposto por Wang (2014), onde a atividade forte apresenta CIM $>10 \mu \mathrm{g} / \mathrm{mL}$, forte-moderada (CIM $10-100 \mu \mathrm{g} / \mathrm{mL}$ ), fraca-moderada (CIM $100-1000 \mu \mathrm{g} / \mathrm{mL}$ ) e fraca (CIM < $1000 \mu \mathrm{g} / \mathrm{mL}$ ). Os produtos naturais de origem vegetal foram agrupados na Tabelas 1 e os de origem animal na Tabela 2, com o nome do produto ou nome científico da planta, seu tipo de obtenção (fração e/ou extrato), concentração inibitória mínima, cepas bacterianas, autor e ano de publicação. Os estudos clínicos e in vivo foram agrupados na Tabela 3 .

\section{RESULTADOS E DISCUSSÃO}

Essa pesquisa resultou em 1491 artigos de interesse na primeira etapa, foram excluídos 1360 artigos na segunda etapa por não apresentarem atividade antibacteriana com concentração inibitória mínima ou dose, entre outros critérios de elegibilidade descrito na metodologia. Desconsiderando os artigos duplicados nas bases de dados pesquisadas, um total de 138 artigos foram analisados, dos quais 79 são artigos novos encontrados que se somam a 59 artigos integrados da revisão de Wang (2014). Nesses 138 artigos, 128 avaliaram a atividade anti - Helicobacter pylori pela CIM, os outros 10 tratam de estudos in vivo e clínicos. Neles foram encontrados 162 produtos naturais com atividade anti-Helicobacter pylori, que foram alocados em 3 tabelas, utilizando a classificação proposta por Wang (2014). A grande maioria dos produtos encontrados são derivados de plantas medicinais (158/162) e estão listados na Tabela 1., 12 artigos mostram produtos de origem animal (mel, própolis e iogurte), que estão mostrados na Tabela 2 e na Tabela 3, foram inseridos os 10 artigos com estudos clínicos e estudos in vivo e ainda encontramos 4 artigos com produtos originários de fungos com atividade anti-H. pylori. Vinte e seis produtos foram avaliados em mais de um artigo, alguns com concentrações inibitórias mínimas distintas (Tabela 1 e 2),

Aproximadamente $12,5 \%(16 / 128)$ dos produtos naturais exibiram atividade forte, e todos como frações purificadas, exceto extrato de plantas e Impatiens balsamina (Tabela 1 e 2). Os produtos naturais que apresentaram atividade forte-moderada representam 35,1\% dos produtos (45/128), as menores concentrações inibitórias foram provenientes de frações. Os produtos com atividade moderada-fraca representam $28,9 \%$ dos produtos, e a maioria deles foram extratos (37/128). Os produtos com atividade fraca representam $23,5 \%(30 / 128)$ e todos como extrato. 
Tabela 1. Produtos naturais de origem vegetal com atividade anti-Helicobacter pylori, divididos de acordo com a classificação de atividade anti-Helicobacter pylori de Wang (2014).

\begin{tabular}{|c|c|c|c|c|}
\hline Produto Natural & Tipo de produto e extração & $\begin{array}{c}\mathrm{CIM} \\
(\mu \mathrm{g} / \mathrm{mL})\end{array}$ & Cepas HP & Autor \\
\hline \multicolumn{5}{|c|}{ Atividade forte (CIM: $<10 \mu \mathrm{g} / \mathrm{mL}$ ) } \\
\hline Sclerocarya birrea & fração (terpinen-4-ol) & $\begin{array}{c}0,004 \text { a } \\
0,06\end{array}$ & ATCC 43526 & Njume et al., 2011 \\
\hline Evodia rutaecarpa & fração (alcaloide) & $<0,05$ & ATCC 43504 & Hamasaki et al., 2000 \\
\hline Dittrichia viscosa & $\begin{array}{l}\text { óleo essencial bruto e frações } \\
\text { oxigenadas }\end{array}$ & 0,025 & CCUG 15818 & Miguel et al., 2008 \\
\hline Impatiens balsamina & acetona (extrato) & $\begin{array}{c}0,625 \text { a } \\
2,5\end{array}$ & $\begin{array}{c}\text { ATCC 700824, } 43504 \text { e } \\
43526\end{array}$ & Wang et al., 2011 \\
\hline Extrato de plantas & água e metanol (extrato) & $\begin{array}{l}>0,625 \text { a } \\
>5\end{array}$ & Isolados clínicos & Cogo et al., 2010 \\
\hline $\begin{array}{l}\text { Casimiroa tetrameria, Dorstenia contrajerva, } \\
\text { Jatropha gaumeri e Piscidia piscipula }\end{array}$ & metanol e diclometano (extrato) & $0,7-10$ & ATCC 43504 & Ankli et al., 2002 \\
\hline Boronia pinnata & fração (geraniloxicumarinas) & 1,62 & Isolados clínicos & Epifano et al., 2006 \\
\hline Pteleopsis suberosa & fração (saponinas e agliconas) & $1,9-7,8$ & Isolados clínicos & De Leo et al., 2006 \\
\hline Rabdosia trichocarpa & fração (Trichorabdal A) & $2,5-5$ & Isolados clínicos & Kadota et al., 1997 \\
\hline Rubus ulmifolius & fração (polifenóis) & $2-10$ & Isolados clínicos & Martini et al., 2009 \\
\hline Polygonum tinctorium & $\begin{array}{l}\text { fração (metoxy kaempferol, 3,5,4'-tri- } \\
\text { hidroxi-6,7-metilenodioxiflavona e } \\
\text { triptantina) }\end{array}$ & 2,5 & Isolados clínicos & $\begin{array}{l}\text { Hashimoto et al., } \\
1998\end{array}$ \\
\hline Tabebuia impetiginosa & $\begin{array}{l}\text { fração (2- (Hidroximetil) antraquinona e } \\
\text { ácido antraquinona-2-carboxílico) }\end{array}$ & $2-8$ & ATTC 43504 & Park et al., 2006 \\
\hline Tinospora sagittata & fração (palmatina) & $\begin{array}{c}3,12- \\
6,25\end{array}$ & SCYA201401 & Rong et al., 2016 \\
\hline Myroxylon peruiferum & fração (cabreuvin) & 7,8 & ATCC 43504 & Ohsaki et al., 1999 \\
\hline Andrographis paniculata & fração (diterpenos labdânicos) & 9 & ATCC 43526 & Shaikh et al., 2016 \\
\hline \multicolumn{5}{|c|}{ Atividade forte-moderada (CIM: $10-100 \mu \mathrm{g} / \mathrm{mL}$ ) } \\
\hline Tabebuia impetiginosa & fração (idebenona) & $0,8-25$ & ATCC 43504 & Inatsu et al., 2006 \\
\hline Alchemilla monticola & metanol (extrato) & $2-16$ & $\begin{array}{l}\text { ATCC } 43504 \text { e isolados } \\
\text { clínicos }\end{array}$ & Krivokuća et al., 2015 \\
\hline Crocus sativus & etanol (extrato) & $2-32$ & ATCC 43504 & De Monte et al 2015 \\
\hline Piper multiplinervium & metanol (extrato) & $\begin{array}{c}3,75- \\
12,5\end{array}$ & isolados clínicos & Rüegg et al., 2006 \\
\hline Cistus laurifolius & fração (quercetina 3-metil éter) & $\begin{array}{l}3,9- \\
62,5\end{array}$ & NCTC 11637 & Ustün et al., 2006 \\
\hline Geranium wilfordii & etanol (extrato) & $4-40$ & ATCC 43504 & Zhang et al., 2013 \\
\hline Curcuma longa & água (extrato) & $5-50$ & $\begin{array}{l}\text { ATCC } 43504 \text { e isolados } \\
\text { clínicos }\end{array}$ & De et al., 2009 \\
\hline Sideritis italica & fração (óleo essencial) & $5-25$ & $\begin{array}{l}\text { ATCC } 43504 \text { e isolados } \\
\text { clínicos }\end{array}$ & Basile et al., 2006 \\
\hline Feijoa sellowiana & fração (flavona) & $5-25$ & $\begin{array}{l}\text { ATCC } 43504 \text { e isolados } \\
\text { clínicos }\end{array}$ & Basile et al., 2010 \\
\hline Ferulago campestris & fração (cumarina) & $5-25$ & $\begin{array}{l}\text { ATCC } 43504 \text { e isolados } \\
\text { clínicos }\end{array}$ & Basile et al., 2009 \\
\hline Licorice & $\begin{array}{c}\text { fração (glabridina e glabreno, } \\
\text { licochalcona A, licoricidina e } \\
\text { licoisoflavona B }\end{array}$ & $6,25-50$ & ATCC 43504 & Fukai et al., 2002 \\
\hline Anthemis altissima & $\begin{array}{l}\text { fração (kaempferol, quercetina, } \\
\text { rhamnetina e isoquercetrina) }\end{array}$ & $6,25-50$ & ATCC 43504 & $\begin{array}{l}\text { Konstantinopoulou et } \\
\text { al., } 2003\end{array}$ \\
\hline $\begin{array}{l}\text { Plantas medicinais mexicanas (Persea americana, } \\
\text { Guaiacum coulteri, Annona cherimola e Moussonia } \\
\text { deppeana) }\end{array}$ & água e etanol (extrato) & $\begin{array}{l}7,5- \\
15,6\end{array}$ & ATCC 43504 & $\begin{array}{c}\text { Castillo-Juárez et al., } \\
2007\end{array}$ \\
\hline Tabebuia impetiginosa & etanol e acetato de etila (extrato) & $9-30$ & isolados clínicos & Zhang et al., 2010 \\
\hline Magnolia officinalis & fração (magnolol) & $10-20$ & $\begin{array}{l}\text { ATCC43504, NCTC11637 e } \\
\text { 11638 e isolados clínicos } \\
\text { (HP82516, HP82548 e HP4) }\end{array}$ & Bae et al., 1998 \\
\hline Rosa (hibrida) & etanol e butanol (extrato) & $10-100$ & ATCC 49503 & Park et al., 2016 \\
\hline Pueraria thunbergiana & fração (irisolidona) & $12-100$ & $\begin{array}{l}\text { ATCC43504, NCTC11637 e } \\
11638 \text { e isolados clínicos } \\
\text { (HP82516, HP82548 e HP4) }\end{array}$ & Bae et al., 2001 \\
\hline Psoralea corylifolia & Fração (Psoracorylifols) & $12,5-25$ & ATCC 43504 & Yin et al., 2005 \\
\hline Myristica fragrans e Rosmarinus officinalis & metanol (extrato) & $12,5-25$ & $\begin{array}{l}\text { ATCC } 43504 \text { e isolados } \\
\text { clínicos }\end{array}$ & Mahady et al., 2003 \\
\hline Sanguinaria canadensis e Hydrastis canadensis & água e metanol (extrato) & $12,5-50$ & ATCC 43504 & Mahady et al., 2003 \\
\hline $\begin{array}{l}\text { Carum carvi, Elettaria cardamomum, Gentiana } \\
\text { lutea, Juniperus communis, Lavandula angustifolia, } \\
\text { Melissa officinalis, Mentha x piperita e Pimpinella } \\
\text { anisum }\end{array}$ & Metanol & $14,5-58$ & $\begin{array}{l}\text { Isolados clínicos e ATCC } \\
43504\end{array}$ & Mahady et al., 2003 \\
\hline
\end{tabular}




\begin{tabular}{|c|c|c|c|c|}
\hline Chá de plantas comestiveis & acetato de etila e metanol (extrato) & 15,6 & DMST 20979 & Sakunpak et al., 2012 \\
\hline Parthenium hysterophorus & diclorometano e água (extrato) & 15,6 & ATCC 43504 & $\begin{array}{l}\text { Espinosa-Rivero et } \\
\text { al., } 2015\end{array}$ \\
\hline $\begin{array}{l}\text { Curcuma amada, Mallotus phillipinesis, Myrisctica } \\
\text { fragrans e Psoralea corylifolia }\end{array}$ & etanol (extrato) & $\begin{array}{c}15,6- \\
62,5\end{array}$ & ATCC 43504 & Zaidi et al., 2009 \\
\hline Chenopodium ambrosioides & água (extrato) & 16 & NCTC11637 & Ye et al., 2016 \\
\hline Leonotis nepetifolia & água e etanol (extrato) & 25 & ATCC 43504 & Oliveira et al., 2015 \\
\hline Vinho tinto & extrato bruto & $25-100$ & $\begin{array}{l}\text { ATCC } 700392 \text { e } 700824 \text { e } \\
\text { isolados clínicos }\end{array}$ & Paulo et al., 2011 \\
\hline Enantia chlorantha & água (extrato) & 39 & ATCC 43504 & Tan et al., 2010 \\
\hline $\begin{array}{l}\text { Abrus cantoniensis, Saussurea lappa e Eugenia } \\
\text { caryophyllata }\end{array}$ & água e etanol (extrato) & 40 & ATCC 43504 & Li et al., 2005 \\
\hline Larrea divaricata & água (extrato) & $40-100$ & ATCC 43504 & Stege et al., 2006 \\
\hline Allium sativum & fração (allixin) & 50 & ATCC 43504 & Mahady et al., 2001 \\
\hline Ginseng Panax & $\begin{array}{l}\text { frações (poliacetilenos e } \\
\text { protopanaxatriol) }\end{array}$ & 50 & $\begin{array}{l}\text { ATCC43504, NCTC11637 e } \\
11638 \text { e isolados clínicos } \\
\text { (HP82516, HP82548 e HP4) }\end{array}$ & Bae et al., 2001 \\
\hline Cinnamomum verum & etanol (extrato) & 50 & isolados clínicos & Tabak et al., 1999 \\
\hline $\begin{array}{l}\text { Achillea millefolium, Foeniculum vulgare, Passiflora } \\
\text { incarnata e Origanum majorana }\end{array}$ & metanol (extrato) & $50-100$ & $\begin{array}{l}\text { ATCC } 43504 \text { e isolados } \\
\text { clínicos }\end{array}$ & Mahady et al., 2001 \\
\hline $\begin{array}{l}\text { Hippophae hamnoides, Fritillaria thunbergii, } \\
\text { Magnolia officinalis, Schisandra chinensis, } \\
\text { Corydalis yanhusuo, Citrus reticulata, Bupleurum } \\
\text { chinense e Ligusticum chuanxiong }\end{array}$ & água e etanol (extrato) & 60 & ATCC 43504 & Li et al., 2005 \\
\hline Myroxylon peruiferum & fração (cabreuvina) & 62,5 & ATCC 43504 & Ohsaki et al., 1999 \\
\hline $\begin{array}{l}\text { Bidens pilosa, Galinsoga ciliata e Eryngium } \\
\text { foetidum }\end{array}$ & metanol (extrato) & 64 & isolados clínicos & $\begin{array}{l}\text { Kouitcheu Mabeku et } \\
\text { al., } 2016\end{array}$ \\
\hline Camomila, flor de laranjeira e gengibre & fração (óleo essencial) & 65 & ATCC 43504 & Weseler et al., 2005 \\
\hline Patchouli & fração (óleo essencial) & 78 & ATCC 43504 & Yu et al., 2014 \\
\hline Aloysia triphylla e Inula viscosa & Etanol (extrato) & $83-90$ & isolados clínicos & Masadeh et al 2014 \\
\hline $\begin{array}{l}\text { Carum carvi, Elettaria, cardamomum, Gentiana } \\
\text { lutea, Juniper communis, Lavandula angustifolia, } \\
\text { Melissa officinalis, Mentha piperita e Pimpinella } \\
\text { anisum }\end{array}$ & metanol (extrato) & 100 & $\begin{array}{l}\text { isolados clínicos e ATCC } \\
43504\end{array}$ & Mahady et al., 2003 \\
\hline
\end{tabular}

\begin{tabular}{|c|c|c|c|c|}
\hline \multicolumn{5}{|c|}{ Atividade fraca-moderada (CIM $100-1000 \mu \mathrm{g} / \mathrm{mL}$ ) } \\
\hline Alchemilla glabra & metanol, diclorometano e cicloexano & $2-256$ & $\begin{array}{l}\text { Isolados clínicos e ATCC } \\
43504\end{array}$ & Krivokuća et al., 2015 \\
\hline Aristolochia paucinervis & fração (rizoma) & $4-128$ & ATCC 43504 & Gadhi et al., 2001 \\
\hline Aloe vera & Extrato & $\begin{array}{c}6,25- \\
800\end{array}$ & ATCC 43504 & Cellini et al., 2014 \\
\hline $\begin{array}{l}\text { Acacia nilotica, Calotropis procera, Adhatoda } \\
\text { vasica, Fagonia arabica e Casuarina equisetifolia }\end{array}$ & água, acetona e metanol (extrato) & $8-256$ & ATCC 43504 & Amin et al., 2013 \\
\hline Piper multiplinervium & $\begin{array}{l}\text { Fração (galato de epigalocatequina e } \\
\text { epicatequina) }\end{array}$ & $8-256$ & АTTC 43504 & Mabe et al \\
\hline $\begin{array}{l}\text { Plantas medicinais } \\
\text { Ferula pseudalliacea }\end{array}$ & $\begin{array}{l}\text { frações (taninos hidrolizados) } \\
\text { fração (coquino disesquiterpeno e } \\
\text { cumarinas sesquiterpenos) }\end{array}$ & $\begin{array}{c}12,5- \\
400 \\
16-128\end{array}$ & $\begin{array}{c}\text { NCTC } 11638 \text { e ATCC } 43504 \\
\text { e isolados clínicos } \\
\text { Isolados clínicos }\end{array}$ & $\begin{array}{l}\text { Funatogawa et al., } \\
2004 \\
\text { Dastan et al., } 2016\end{array}$ \\
\hline Lycopodium cernuum & etanol (extrato & $\begin{array}{c}16- \\
1000\end{array}$ & ATCC 43504 & Ndip et al., 2008 \\
\hline Tephrosia purpurea & etanol (extrato) & $25-400$ & ATCC 43504 & Chinniah et al., 2009 \\
\hline Pteleopsis suberosa & etanol (extrato) & $\begin{array}{c}31,25- \\
250\end{array}$ & ATCC 43504 & Germanò et al., 1998 \\
\hline Trachyspermum copticum e Xanthium brasilicum & fração e etanol (extrato) & $\begin{array}{c}31,25- \\
250\end{array}$ & ATCC 43504 & Nariman et al 2004 \\
\hline Gymnosperma glutinosum & etanol (extrato) & $\begin{array}{c}31,25- \\
500\end{array}$ & ATCC 43504 & $\begin{array}{l}\text { Gomez-Flores et al } \\
2016\end{array}$ \\
\hline Zingiber Zerumbet & etanol (extrato) & $\begin{array}{c}31,25- \\
250\end{array}$ & $\begin{array}{c}\text { ATCC } 43504 \text { e ATCC } \\
700824\end{array}$ & Sidahmed et al 2015 \\
\hline Bryophyllum pinnatum & metanol e acetato de etila (extrato) & $32-512$ & Isolados clínicos & Mabeku et al 2017 \\
\hline Plantas medicinais (Camarões) & metanol (extrato) & $\begin{array}{c}32- \\
1000\end{array}$ & Isolados clínicos & Ndip et al., 2007 \\
\hline Chamomilla recutita & água e etanol (extrato) & $\begin{array}{c}62,5- \\
125\end{array}$ & ATCC 43504 & Shikov et al., 2008 \\
\hline $\begin{array}{l}\text { Ageratum conyzoides, Scleria striatinux, } \\
\text { Lycopodium }\end{array}$ & etanol (extrato) & $\begin{array}{c}63- \\
1000\end{array}$ & Isolados clínicos & Ndip et al., 2008 \\
\hline Uva muscadine (Vitis rotundifolia & Acetona, água, ácido acético e metanol & $64-128$ & Isolados clínicos & Brown et al., 2009 \\
\hline Rhus verniciflua & etanol (extrato) & $64-256$ & ATCC 43504 & Suk et al., 2010 \\
\hline Vinho tinto & Fração & $80-200$ & ATCC 43504 & Bae et al., 1998 \\
\hline Paeonia lactiflora & etanol (extrato) & $80-320$ & ATCC 43504 & Ngan et al., 2012 \\
\hline Terminalia macroptera & etanol (extrato) & $\begin{array}{l}100- \\
200\end{array}$ & ATCC 43504 & Silva et al., 2012 \\
\hline Pimentão verde (Capsicum annuum) & fração e água (extrato) & $>100$ & isolados clínicos & $\begin{array}{l}\text { Ilona mucsie et al., } \\
2001\end{array}$ \\
\hline Teminalia chebula & água (extrato) & 125 & ATCC 43504 & $\begin{array}{l}\text { Malekzadeh et al., } \\
2001\end{array}$ \\
\hline Paepalanthus bromelioides & fração (isocoumarina paepalantina) & 128 & ATCC 43504 & $\begin{array}{l}\text { Damasceno et al } \\
2017\end{array}$ \\
\hline Aframomum pruinosum & metanol (extrato) & 128 & ATCC 43504 & Mabeku et al 2017 \\
\hline Rubus ulmifolius & Extrato & $\begin{array}{c}134- \\
270\end{array}$ & ATCC 43504 & Martini et al., 2009 \\
\hline
\end{tabular}




\begin{tabular}{|c|c|c|c|c|}
\hline Amphipterygium adstringens & fração (éter de petróleo) & 160 & ATCC 43504 & $\begin{array}{l}\text { Castillo-Juárez et al., } \\
\qquad 2007\end{array}$ \\
\hline Rhizophora mangle & água (extrato) & $\begin{array}{c}180- \\
210\end{array}$ & ATCC 43504 & Perera et al., 2017 \\
\hline Plantas medicinais mexicanas & etanol (extrato) & $\begin{array}{c}200- \\
400\end{array}$ & ATCC 43504 & $\begin{array}{l}\text { Robles-Zepeda et al., } \\
\qquad 2011\end{array}$ \\
\hline Bryophyllum pinnatum & Metanol e acetato de etila & $32-512$ & Isolados clínicos & Mabeku et al., 2017 \\
\hline Bacopa monnieri & Etanol & 1000 & Isolados clínicos & Goel et al., 2003 \\
\hline \multicolumn{5}{|c|}{ Atividade fraca (CIM:> $1000 \mu \mathrm{g} / \mathrm{mL}$ ) } \\
\hline Bridelia micrantha & etanol (extrato) & $\begin{array}{c}48- \\
2500\end{array}$ & Isolados clínicos & Okeleye et al., 2011 \\
\hline Sclerocarya birrea & etanol (extrato) & $\begin{array}{l}60- \\
2500\end{array}$ & Isolados clínicos & Njume et al., 2011 \\
\hline $\begin{array}{l}\text { Terminalia spinosa, Harrisonia abyssinica, Ximenia } \\
\text { caffra, Azadirachta indica e Spilanthes mauritiana }\end{array}$ & metanol (extrato) & $\begin{array}{c}62,5-> \\
4000\end{array}$ & ATCC 43504 & Fabry et al 1996 \\
\hline Eucalipto & etanol (extrato) & $\begin{array}{c}64- \\
1024\end{array}$ & Isolados clínicos & Parreira et al., 2017 \\
\hline Cuminum cyminum & etanol (extrato) & $\begin{array}{c}75- \\
10000\end{array}$ & ATCC 43504 & Nostro et al., 2005 \\
\hline Plantas Fitoterápicas & etanol (extrato) & $\begin{array}{l}160- \\
1460\end{array}$ & Isolados clínicos & Cwikla et al., 2010 \\
\hline $\begin{array}{l}\text { Óleo de Mentha piperita, Origanum vulgare, } \\
\text { Pimpinella anisum, anis e Syzygium aromaticum }\end{array}$ & etanol (extrato) & $\begin{array}{l}160- \\
1460\end{array}$ & Isolados clínicos & Cwikla et al., 2010 \\
\hline Punica granatum e Quercus infectoria & etanol (extrato) & $\begin{array}{c}160-> \\
2500\end{array}$ & Isolados clínicos & $\begin{array}{l}\text { Voravuthikunchai et } \\
\text { al., } 2008\end{array}$ \\
\hline Anacardium occidentale (Castanha) & fração (ácidos anacárdicos) & $\begin{array}{l}200- \\
1600\end{array}$ & Isolados clínicos & Kubo et al., 1999 \\
\hline $\begin{array}{l}\text { Derris malaccensis } \\
\text { Cichorium intybus, Cinnamomum zeylanicum, } \\
\text { Coriandrum sativum, Cuminum cyminum, } \\
\text { Cynara scolymus, } \\
\text { Electaria cardamomum, } \\
\text { Foeniculum vulgare, } \\
\text { Juniperus communis, Mentha piperita, Origanum } \\
\text { vulgare, Prunus avium, Rosmarinus officinalis, } \\
\text { Salvia officinalis, Thymus serpyllum, Tilia } \\
\text { platyphyllos e Zingiber officinalis }\end{array}$ & $\begin{array}{c}\text { frações (rotenona, rotenolona, } \\
\text { desidrorotenona, deguelin, efhlosina, } \\
\text { toxicarol, desidrodegenerina e eliptona) } \\
\text { Água e etanol (extrato) }\end{array}$ & $\begin{array}{c}300- \\
85000 \\
300- \\
100000\end{array}$ & $\begin{array}{l}\text { Isolados clínicos } \\
\text { ATCC } 43629\end{array}$ & $\begin{array}{l}\text { Takashima et al } 2002 \\
\text { Nostro et al., } 2005\end{array}$ \\
\hline Anthemis altissima & Fração (ácido clorogênico) & $\begin{array}{c}312,5 \mathrm{a} \\
1250\end{array}$ & ATCC 43504 & $\begin{array}{c}\text { Konstantinopoulou et } \\
\text { al., } 2003\end{array}$ \\
\hline $\begin{array}{l}\text { Origanum vulgare, Cuminum cyminum e Cynara } \\
\text { scolymus }\end{array}$ & metanol (extrato) & $\begin{array}{c}600- \\
10000\end{array}$ & ATCC 43504 & Nostro et al., 2005 \\
\hline Chamomilla recutita e llex paraguariensis & etanol (extrato) & $\begin{array}{l}625- \\
1250\end{array}$ & ATCC 43504 & Cogo et al., 2010 \\
\hline Allium ascalonicum & Extrato bruto & $\begin{array}{l}625- \\
1250\end{array}$ & ATCC 43504 & Adeniyi et al., 2004 \\
\hline $\begin{array}{l}\text { Anthemis melampodina, Cerastium candidissimum, } \\
\text { Chamomilla recutita, Conyza álbida, Dittrichia } \\
\text { viscosa, Origanum vulgare e Stachys alopecuros }\end{array}$ & etanol (extrato) & $\begin{array}{l}625- \\
5000\end{array}$ & $\begin{array}{l}\text { ATCC } 43504 \text { e isolados } \\
\text { clínicos }\end{array}$ & Stamatis et al., 2003 \\
\hline Terminalia chebula & etanol (extrato) & $\begin{array}{l}1000- \\
2500\end{array}$ & ATCC 43504 & $\begin{array}{l}\text { Malekzadeh et al., } \\
2001\end{array}$ \\
\hline Plumbago zeylanica & metanol (extrato) & $\begin{array}{l}625- \\
5000\end{array}$ & ATCC 43504 & Wang e Huang 2005 \\
\hline $\begin{array}{l}\text { Anisomeles indica, Alpinia speciosa, Zingiberaceae } \\
\text { Martinov, Bombax malabaricum e Paederia } \\
\text { scandens }\end{array}$ & metanol (extrato) & $\begin{array}{c}640- \\
10240\end{array}$ & ATCC 43504 & Wang e Huang 2005 \\
\hline Allium sativum & Etanol (extrato) & $\begin{array}{c}2000- \\
5000\end{array}$ & ATCC 43504 & Cellini et al., 1996 \\
\hline Magnolia sieboldii & $\begin{array}{l}\text { fração (lactona sesquiterpênica } \\
\text { desidrocostal lactona) }\end{array}$ & $\begin{array}{c}4400- \\
4900\end{array}$ & ATCC 700392 e 700824 & Lee et al., 2014 \\
\hline
\end{tabular}

Tabela 2. Produtos naturais de origem animal com atividade anti-Helicobacter pylori, divididos de acordo com a classificação de atividade anti-Helicobacter pylori de Wang (2014).

\begin{tabular}{|c|c|c|c|c|}
\hline Produto Natural & $\begin{array}{c}\text { Tipo de produto e } \\
\text { extração }\end{array}$ & $\mathrm{CIM}(\mu \mathrm{g} / \mathrm{mL})$ & Cepas HP & Autor \\
\hline \multicolumn{5}{|c|}{ Atividade forte (CIM: $<10 \mu \mathrm{g} / \mathrm{mL}$ ) } \\
\hline Mel de acácia coreana & Fração isolada & 2,7 & Isolados clínicos & Kim et al., 2017 \\
\hline \multicolumn{5}{|c|}{ Atividade forte-moderada (CIM: $10-100 \mu \mathrm{g} / \mathrm{mL}$ ) } \\
\hline \multicolumn{5}{|c|}{ Não há registros } \\
\hline
\end{tabular}




\begin{tabular}{|c|c|c|c|c|}
\hline \multicolumn{5}{|c|}{ Atividade fraca-moderada (CIM 100 - 1000 g/mL) } \\
\hline Própolis (Bulgária) & etanol (extrato) & $100-300$ & Isolados clínicos & Boyanova et al., 2005 \\
\hline Mel (Camarões) & água (extrato) & $110-938$ & Isolados clínicos & Ndip et al., 2007 \\
\hline Própolis (Itália) & etanol (extrato) & 750 & Isolados clínicos & Nostro et al., 2005 \\
\hline Própolis (Brasil) & etanol (extrato) & 1000 & Isolados clínicos & Banskota et al., 2001 \\
\hline \multicolumn{5}{|c|}{ Atividade fraca (CIM: > $1000 \mu \mathrm{g} / \mathrm{mL}$ ) } \\
\hline Própolis vermelha (Brasil) & etanol (extrato) & $64-1024$ & Isolados clínicos & $\begin{array}{l}\text { Regueira Neto et al., } \\
\qquad 2017\end{array}$ \\
\hline Mel (Camarões) & $\begin{array}{c}\text { hexano e éter dietílico } \\
\text { (extrato) }\end{array}$ & $78-10000$ & Isolados clínicos & Manyi-Loh et al., 2012 \\
\hline Própolis (Turquia) & etanol (extrato) & $260-1520$ & Isolados clínicos & Baltas et al., 2016 \\
\hline Própolis (Espanha) & Extrato & $6000-14000$ & Isolados clínicos & Bonvehí et al., 2012 \\
\hline Mel (Turquia) & água (extrato) & $12000-39000$ & Isolados clínicos & Sahin 2015 \\
\hline Mel (África do Sul) & Extrato & $10000-12500$ & Isolados clínicos & Manyi-Loh et al., 2013 \\
\hline
\end{tabular}

O produto mais ativo foi a fração de Sclerocarya birrea (CIM: 0,004 - 0,06 $\mu \mathrm{g} / \mathrm{mL}$ ) conhecida como Marula, originária do bioma da Savana da África Oriental e que apresentou concentrações comparáveis à amoxicilina. Para Njume et al., (2011) esse produto é uma fonte promissora anti-H. pylori. Uma fração da Evodia rutaecarpa, erva medicinal chinesa, foi o segundo mais ativo (CIM: 0,05 $\mathrm{g} / \mathrm{mL}$ ), possui atividades anti-inflamatórias, antitumorais, antibacteriana, antivirais, adstringentes e diuréticas (HAMASAKI et al., 2000). Destaca-se ainda o ácido abscísico proveniente do mel de Acacia coreana (CIM: 2,6 $\mathrm{\mu g} / \mathrm{mL}$ ), extraído do néctar das flores da árvore Robinia pseudoacacia. Esse tipo de mel é procurado em todo o mundo por suas propriedades medicinais (KIM et al., 2017). A concentração inibitória mínima apresentada por esses três produtos foi melhor que alguns antibióticos padrões utilizados no tratamento anti-Helicobacter pylori, como a claritromicina, metronidazol e levofloxacino e se equipara a concentração inibitória mínima da amoxicilina, um dos medicamentos mais eficazes na erradicação de H. pylori (WANG et al., 2011).

Os produtos com atividade forte-moderada em sua maioria foram extratos de plantas, patchouli, vinho tinto, uva, alho, ginseng, canela, cúrcuma e rosa (Tabela 1) e de origem animal própolis (Tabela 2). A fração mais ativa foi originária de Tabebuia impetiginosa $(0,5-32 \mu \mathrm{g} / \mathrm{mL})$, popularmente conhecido como ipê-roxo, com propriedades antitumorais, antibacterianas, antioxidantes e antibióticas (PARK et al., 2006; INATSU et al., 2006). Além dos fungos Cetraria islandica, Cantharellus cibarius e Hericium erinaceus (INGOLFSDOTTIR et al., 1997; LIU et al., 2016; KOLUNDŽIĆ et al., 2017).

Com atividade inibitória moderada-fraca se destacam os produtos naturais provenientes de extratos de plantas medicinais chinesas e mexicanas, própolis, mel, aloe vera, pimentão verde e vinho tinto com concentrações de 100 a $1000 \mu \mathrm{g} / \mathrm{mL}$. Entre os produtos com atividade fraca destacam-se óleos de hortelãpimenta e anis, extratos de plantas medicinais, alho, plantas fitoterápicas, uva, eucalipto, castanha de caju, cogumelo, mel e própolis com concentrações de 1000 a $100.000 \mu \mathrm{g} / \mathrm{mL}$, as plantas medicinais de Camarões e a Bridelia micrantha foram os extratos mais ativos. Bridelia micrantha é utilizada na medicina popular para tratar várias condições como cefaleias, conjuntivite, dor abdominal, constipação e gastrite (OKELEYE et al., 2011; SHANG et al., 2013).

Dentre os produtos naturais de origem animal o mel e a própolis merecem destaque, pois possuem propriedades nutracêuticas, descritas na medicina tradicional e em tratamentos alternativos na terapia de cicatrização de feridas até o tratamento antitumoral. Os seus compostos bioativos são responsáveis por 
exercer efeitos antibacterianos, antioxidantes, antiinflamatórios, anticancerígenos, imunomoduladores e antimetastáticos (AJIBOLA et al., 2012; VIUDA-MARTOS et al., 2008).

A maioria dos estudos avaliaram os produtos anti-H. pylori contra cepas bacterianas virulentas (cagA+ e vacA+), os demais avaliaram cepas bacterianas virulentas e isolados clínicos conjuntamente.

Além da classificação proposta por Wang (2014) que é específica para plantas medicinais antiHelicobacter pylori, outros autores classificaram produtos naturais conforme sua atividade de inibição contra outras bactérias. Castillo-Juarez et al. (2009) classificou plantas medicinais conforme seu tipo de extração, água e metanol. Os produtos extraídos do metanol apresentam atividade forte, boa, moderada, baixa e nula (CIM $<125 \mu \mathrm{g} / \mathrm{mL}$ - > $1000 \mu \mathrm{g} / \mathrm{mL}$ ), já os produtos extraídos de água apresentam (CIM $<7,8 \mu \mathrm{g} / \mathrm{mL}->500$ $\mu \mathrm{g} / \mathrm{mL}$ ). Para Aligiannis et al., (2001) e Sartoratto et al., (2004) os produtos com atividade forte apresentam (CIM $50-500 \mu \mathrm{g} / \mathrm{mL}$ ), moderada (CIM $600-1500 \mu \mathrm{g} / \mathrm{mL}$ ) e fraca atividade (CIM > de $1500 \mu \mathrm{g} / \mathrm{mL}$ ). Holetz et al., (2002) apresenta uma classificação mais criteriosa onde os extratos de plantas com forte atividade apresentam (CIM < $100 \mu \mathrm{g} / \mathrm{mL}$ ), moderada (CIM $100-500 \mu \mathrm{g} / \mathrm{mL}$ ), fraca (CIM $500-1000 \mu \mathrm{g} / \mathrm{mL}$ ) e acima de $1000 \mathrm{\mu g} / \mathrm{mL}$ como sem atividade. Critérios alternativos foram descritos ainda por Fabry et al., (1998), ao considerar os extratos com CIM $<8000 \mu \mathrm{g} / \mathrm{mL}$ com atividade antimicrobiana aproveitável.

Para a maioria dos autores o produto natural possui atividade potencialmente promissora, independente da concentração apresentada, sugerindo estudos futuros, no que tange a toxicidade, bem como estudos clínicos que confirmem essa potencialidade. Ainda devemos considerar que não existe um consenso sobre a concentração aceitável para produtos naturais quando comparados com antibióticos conhecidos. Dessa maneira notamos que não existe um consenso sobre a concentração aceitável para produtos naturais derivados de plantas ou não quando comparados a substâncias puras, frações e extratos.

Diante isso, o presente estudo propõe uma nova classificação de produtos naturais com atividade anti-Helicobacter pylori que inclua não só os extratos vegetais, mas também produtos de origem animal e fungos. A nova proposta consta de 5 categorias de acordo com a sua concentração inibitória mínima. Os produtos com atividade forte apresentam (CIM $<50 \mu \mathrm{g} / \mathrm{mL}$ ), atividade boa (CIM $50-500 \mu \mathrm{g} / \mathrm{mL}$ ), atividade

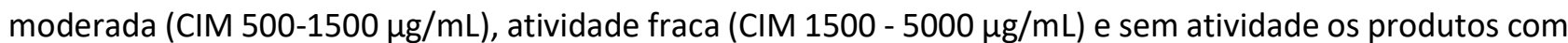
$(\mathrm{CIM}>5000 \mu \mathrm{g} / \mathrm{mL})$.

Com a nova classificação proposta, a faixa de atividade anti-Helicobacter pylori considerada forte foi ampliada para CIM $<50 \mu \mathrm{g} / \mathrm{mL}$. Isso permite que outros produtos, além de frações vegetais, entrem nessa categoria. Esse critério é ainda menor do proposto por Holetz et al. (2012) para bactérias distintas de $H$. pylori. Assim, na classe atividade forte agora encontra-se 42 produtos, sendo 22 extratos e 20 frações. Isso aumentou para $32,8 \%$ de produtos naturais com atividade forte, superior aos $12,5 \%$ da classificação de Wang (2014). Dentre os produtos na nova classificação proposta destacam-se as plantas medicinais, ginseng, alho e o mel de acácia.

$\mathrm{Na}$ classificação dos produtos com atividade boa (CIM 50-500 $\mu \mathrm{g} / \mathrm{mL}$ ) encontra-se 48 produtos $(37,5 \%)$, incluindo plantas medicinais, rosa e própolis (com 34 extratos e 14 frações). Na classificação de atividade moderada (CIM 500-1500 $\mu \mathrm{g} / \mathrm{mL}$ ) encontra-se 16 produtos (12,5\%) e apenas um deles é fração, 
com destaque para plantas medicinais, mel e própolis. Na classificação fraca encontra-se 12 produtos (9,3\%), com 10 extratos e 2 frações, dentre eles mel, própolis, alho, castanha de caju e plantas medicinais. Na classificação sem atividade (CIM >5000 $\mu \mathrm{g} / \mathrm{mL}$ ), valor esse maior do que proposto por Holetz (CIM >1000 $\mu \mathrm{g} / \mathrm{mL}$ ) e menor do que Fabry $(\mathrm{CIM}>8000 \mu \mathrm{g} / \mathrm{mL}$ ) encontra-se 10 produtos naturais $(7,8 \%)$, entre eles própolis, mel, cogumelo e extratos de plantas medicinais.

Os produtos naturais com intervalos amplos de concentração inibitória como extrato de Bridelia micranta (CIM 48 - $2500 \mu \mathrm{g} / \mathrm{mL}$ ) (Okeleye et al., 2011), Derris malaccensis (300 - $85000 \mu \mathrm{g} / \mathrm{mL}$ ) (Takashima et al., 2002) e Cuminum cyminum (CIM 75 - $10000 \mu \mathrm{g} / \mathrm{mL}$ ) (Nostro et al., 2005), necessitam de uma investigação mais completa em suas frações para se adequarem à classificação.

Embora a nova classificação proposta neste trabalho exclua produtos como mel e própolis, que tiveram suas atividades consideradas promissoras por Fabry et al., (1998), devemos levar em consideração que esses produtos fazem parte do cotidiano, geralmente seu uso excede $5 \mathrm{mg}$ por porção e não precisa necessariamente ser usado como produtos com potencial farmacológico, que menores concentrações despertam maior interesse, e sim como terapia complementar à terapia convencional.

A revisão apresenta ainda alguns estudos clínicos com produtos naturais como mel, própolis, alho e uso associado de brócolis com iogurte e alho com jalapeño, e estudos in vivo com plantas como Bidens pilosa, Galinsoga ciliata, Eryngium foetidum, Tinospora sagittata e cúrcuma, todos com resultados considerados promissores pelos autores (Tabela 3 ).

Com essa nova classificação ampliou-se os parâmetros estabelecidos com abrangência de outros produtos naturais com potencial antibacteriano semelhantes aos antibióticos convencionais. Além disso, notamos que outros produtos como mel e própolis, que são de fácil acesso a população de uma forma geral, passam a fazer parte de quatro classificações diferentes e não somente como atividade fraca ou sem atividade.

Tabela 3. Produtos naturais com atividade anti-Helicobacter pylori em estudos clínico e pré-clínico.

\begin{tabular}{|c|c|c|c|c|}
\hline \multicolumn{5}{|c|}{ ESTUDO CLÍNICO } \\
\hline Produto Natural & Tipo de produto e extração & DOSE & Resultado & Autor \\
\hline Mel (Turquia) & $\begin{array}{l}\text { Nigella sativa (óleo de } \\
\text { semente) }\end{array}$ & $5 \mathrm{ml}$ & Positivo & $\begin{array}{l}\text { Mohtashami et al., } \\
2015\end{array}$ \\
\hline Mel (Bulgária) & mel in natura & indefinido & Positivo & Boyanova et al., 2015 \\
\hline Mel (Nova Zelândia) & mel in natura & $\begin{array}{l}1 \text { colher sopa ( } 4 x \\
\text { semana) }\end{array}$ & Negativo & Mcgovern et al., 1999 \\
\hline Própolis Verde (Brasil) & Etanol (extrato) & $\begin{array}{c}20 \text { gotas } \\
\text { (3x/dia/7dia/seman } \\
\text { a) }\end{array}$ & Negativo & Coelho et al., 2007 \\
\hline $\begin{array}{l}\text { Brassica oleracea (Brócolis } \\
\text { com iogurte) }\end{array}$ & in natura & $135 \mathrm{~g} / \mathrm{dia}$ & Negativo & Opekun et al., 2005 \\
\hline Allium sativum (Alho) & cru ou cozido & indefinido & Positivo & Salih et al., 2003 \\
\hline $\begin{array}{l}\text { Allium sativum e Capsicum } \\
\text { annuum (Alho e jalapeño) }\end{array}$ & in natura & $\begin{array}{c}10 \text { fatias alho e } 6 \\
\text { jalapenhos por } \\
\text { refeição }\end{array}$ & Negativo & Graham et al., 1999 \\
\hline \multicolumn{5}{|c|}{ ESTUDO PRÉ-CLÍNICO } \\
\hline Produto Natural & Tipo de produto e extração & Dose $(\mathrm{mg} / \mathrm{ml})$ & Resultado & Autor \\
\hline $\begin{array}{l}\text { Bidens pilosa, Galinsoga } \\
\text { ciliata e Eryngium foetidum }\end{array}$ & Etanol (extrato) & $\begin{array}{c}125,250 \text { e } 500 \\
\mathrm{mg} / \mathrm{kg}\end{array}$ & Positivo & $\begin{array}{c}\text { Kouitcheu Mabeku et } \\
\text { al., } 2016\end{array}$ \\
\hline Tinospora sagittata & Etanol (extrato) & indefinido & $80 \%$ de inibição & Rong et al., 2016 \\
\hline
\end{tabular}




\section{CONCLUSÕES}

Este trabalho propôs uma nova classificação de produtos naturais de produtos com atividade antiHelicobacter pylori com base numa revisão de literatura. As concentrações inibitórias mínima foram utilizadas como parâmetro de classificação e variaram de 0,004 a $100.000 \mu \mathrm{g} / \mathrm{mL}$.

A proposição de uma nova classificação da concentração inibitória mínima traz a possibilidade de inclusão de diversos produtos, além de plantas medicinais com atividade forte anti-Helicobacter pylori, com a presença de frações e extratos de plantas medicinais e mel.

A nova classificação proposta permitiu a inclusão de outros extratos vegetais, produtos de origem animal e fungos com atividade anti-Helicobacter pylori, e ampliou a faixa de produtos considerados com forte atividade, incluindo outros produtos, não só substâncias puras e frações de plantas medicinais, alguns com concentração inibitória mínima semelhante aos antibióticos utilizados em terapias convencionais.

AGRADECIMENTOS: a Domingos Tabajara Martins de Oliveira pelas contribuições.

\section{REFERÊNCIAS}

ADENIYI, B. A.; ANYIAM, F, M.. In vitro anti-Helicobacter pylori potential of methanol extract of Allium ascalonicum Linn. (Liliaceae) leaf: susceptibility and effect on urease activity. Phytotherapy research, v. 18, n. 5, p. 358-361, 2004. DOI: http://doi.org/10.1002/ptr.1265

AJIBOLA, A.; CHAMUNORWA, J. P.; ERLWANGER, K. H.. Nutraceutical values of natural honey and its contribution to human health and wealth. Nutrition \& metabolism, v. 9, n. 1, p. 61, 2012. DOI: http://doi.org/10.1186/1743-7075-9-61

ALIGIANNIS, N.; KALPOUTZAKIS, E.; MITAKU, S.; CHINOU, I. B.. Composition and antimicrobial activity of the essential oils of two Origanum species. Journal of agricultural and food chemistry, v. 49, n. 9, p. 4168-4170, 2001. DOI: http://doi.org/10.1021/jf001494m

AMIN, M.; ANWAR, F., NAZ, F., MEHMOOD, T., \& SAARI, N.. Anti-Helicobacter pylori and urease inhibition activities of some traditional medicinal plants. Molecules, v. 18, n. 2, p. 2135-2149, 2013. DOI: http://doi.org/10.3390/molecules18022135

ANKLI, A., Heinrich, M., Bork, P., Wolfram, L., Bauerian, P., Brun, R., Wasescha, M.. Yucatec Mayan medicinal plants: evaluation based on indigenous uses. Journal of Ethnopharmacology, 79(1), 43-52. DOI: https://doi.org/10.1016/S0378-8741(01)00355-5

BAE, E. A., JOO HAN, M., \& KIM, D. H. (2001). in Vitro AntiHelicobacter pylori Activity of Irisolidone Isolated from the Flowers and Rhizomes of Puercirici. Planta med, 67, 161163.

BAE, E. A.; HAN, M. J.; KIM, N. J.; \& KIM, D. H. (1998). AntiHelicobacter pylori Activity of Hearbal Medicines. Biological and Pharmaceutical Bulletin, 21(9), 990-992. DOI: http://doi.org/10.1248/bpb.21.990

BALTAS, N., KARAOGLU, S. A., TARAKCI, C., \& KOLAYLI, S. (2016). Effect of propolis in gastric disorders: inhibition studies on the growth of Helicobacter pylori and production of its urease. Journal of enzyme inhibition and medicinal chemistry, 31(sup2), 46-50. DOI: http://doi.org/10.1080/14756366.2016.1186023

BANSKOTA, A. H., TEZUKA, Y., ADNYANA, I. K., ISHII, E., MIDORIKAWA, K., MATSUSHIGE, K., \& KADOTA, S.. Hepatoprotective and anti-Helicobacter pylori activities of constituents from Brazilian propolis. Phytomedicine, v. 8, n. 1, p. 16-23, 2001. DOI: https://doi.org/10.1078/0944-7113$\underline{00004}$

BASILE, A., CONTE, B., RIGANO, D., SENATORE, F., \& SORBO, S. (2010). Antibacterial and antifungal properties of acetonic extract of Feijoa sellowiana fruits and its effect on Helicobacter pylori growth. Journal of medicinal food, 13(1), 189-195. DOI: https://doi.org/10.1089/imf.2008.0301

BASILE, A., SENATORE, F., GARGANO, R., SORBO, S., DEL PEZZO, M., LAVITOLA, A., VUOTTO, M. L.. (2006). Antibacterial and antioxidant activities in Sideritis italica (Miller) Greuter et Burdet essential oils. Journal of ethnopharmacology, 107(2), 240-248. DOI: https://doi.org/10.1016/j.jep.2006.03.019

BASILE, A., SORBO, S., SPADARO, V., BRUNO, M., MAGGIO, A., FARAONE, N., \& ROSSELLI, S.. Antimicrobial and antioxidant activities of coumarins from the roots of Ferulago campestris (Apiaceae). Molecules, v. 14, n. 3, p. 939-952, 2009. DOI: https://doi.org/10.3390/molecules14030939 
BONVEHÍ, JOSEP SERRA; GUTIÉRREZ, ARRATE LACALLE.. The antimicrobial effects of propolis collected in different regions in the Basque Country (Northern Spain). World Journal of Microbiology and Biotechnology, v. 28, n. 4, p. 1351-1358, 2012. DOI: https://doi.org/10.1007/s11274-011$\underline{0932-y}$

BOYANOVA, L., GERGOVA, G., NIKOLOV, R., DEREJIAN, S., LAZAROVA, E., KATSAROV, N., ... \& KRASTEV, Z.. Activity of Bulgarian propolis against 94 Helicobacter pylori strains in vitro by agar-well diffusion, agar dilution and disc diffusion methods. Journal of medical microbiology, v. 54, n. 5, p. 481-483, 2005. DOI: https://doi.org/10.1099/jmm.0.45880-0

BOYANOVA, L., ILIEVA, J., GERGOVA, G., VLADIMIROV, B., NIKOLOV, R., \& MITOV, I. (2015). Honey and green/black tea consumption may reduce the risk of Helicobacter pylori infection. Diagnostic microbiology and infectious disease, 82(1), 85-86.

https://doi.org/10.1016/j.diagmicrobio.2015.03.001

BRASIL. Agência Nacional de Vigilância Sanitária (ANVISA).

BROWN, J. C., HUANG, G., HALEY-ZITLIN, V., JIANG, X.. Antibacterial effects of grape extracts on Helicobacter pylori. Applied and environmental microbiology, v. 75, n. 3, p. 848852, 2009. DOI: https://doi.org/10.1128/AEM.01595-08

CASTILLO-JUÁREZ, I., GONZÁLEZ, V., JAIME-AGUILAR, H., MARTÍNEZ, G., LINARES, E., BYE, R., ROMERO, I. (2009). AntiHelicobacter pylori activity of plants used in Mexican traditional medicine for gastrointestinal disorders. Journal of ethnopharmacology, 122(2), 402-405, 2009. DOI: https://doi.org/10.1016/j.jep.2008.12.021

CASTILLO-JUÁREZ, I., RIVERO-CRUZ, F., CELIS, H., ROMERO, I.. Anti-Helicobacter pylori activity of anacardic acids from Amphipterygium adstringens. Journal of ethnopharmacology, 114(1), 72-77. 2007. DOI: https://doi.org/10.1016/j.jep.2007.07.022

CELLINI, L., DI BARTOLOMEO, S., DI CAMPLI, E., GENOVESE, S., LOCATELLI, M., DI GIULIO, M. (2014). In vitro activity of Aloe vera inner gel against Helicobacter pylori strains. Letters in applied microbiology, 59(1), 43-48, 2014. DOI: https://doi.org/10.1111/lam.12241

CELLINI, L., DI CAMPLI, E., MASULLI, M., DI BARTOLOMEO, S., ALLOCATI, N. (1996). Inhibition of Helicobacter pylori by garlic extract (Allium sativum). FEMS Immunology \& Medical Microbiology, 13(4), 273-277. DOI: https://doi.org/10.1111/j.1574-695X.1996.tb00251.x

CHINNIAH, A., MOHAPATRA, S., GOSWAMI, S., MAHAPATRA A., KAR, S. K., MALLAVADHANI, U. V., DAS, P. K. (2009). On the potential of Tephrosia purpurea as anti-Helicobacter pylori agent. Journal of ethnopharmacology, 124(3), 642645, 2009. DOI: https://doi.org/10.1016/j.jep.2009.05.016

COELHO, L. G., BASTOS, E. M., RESENDE, C. C., E SILVA, P., SANCHES, B. S., DE CASTRO, F. J. TRINDADE, O. R. (2007). Brazilian green propolis on Helicobacter pylori infection. a pilot clinical study. Helicobacter, 12(5), 572-574. DOI: https://doi.org/10.1111/j.1523-5378.2007.00525.x

COGO, L. L., MONTEIRO, C. L. B., MIGUEL, M. D., MIGUEL, O. G., CUNICO, M. M., RIBEIRO, M. L., COSTA, L. M. D. (2010).
Anti-Helicobacter pylori activity of plant extracts traditionally used for the treatment of gastrointestinal disorders. Brazilian Journal of Microbiology, 41(2), 304-309. DOI: http://dx.doi.org/10.1590/S1517-83822010000200007

CWIKLA, C., SCHMIDT, K., MATTHIAS, A., BONE, K. M., LEHMANN, R., \& TIRALONGO, E. (2010). Investigations into the antibacterial activities of phytotherapeutics against Helicobacter pylori and Campylobacter jejuni. Phytotherapy Research, 24(5), 649-656. 2010. DOI: http://dx.doi.org/10.1002/ptr.2933

D'AGOSTINO, M., DINI, I., RAMUNDO, E., \& SENATORE, F. (1998). Flavonoid glycosides of Alchemilla vulgaris $L$.

Phytotherapy Research: An International Journal Devoted to Pharmacological and Toxicological Evaluation of Natural Product Derivatives, 12(S1), S162-S163. DOI:

http://dx.doi.org/10.1002/(SICI)10991573(1998)12:1+<S162:AID-PTR284>3.0.CO;2-P

DAMASCENO, J. P. L., RODRIGUES, R. P., GONÇALVES, R. D. C. R., KITAGAWA, R. R. (2017). Anti-Helicobacter pylori Activity of Isocoumarin Paepalantine: Morphological and Molecular Docking Analysis. Molecules, 22(5), 786., 2017. DOI: http://dx.doi.org/10.3390/molecules22050786

DASTAN, D., SALEHI, P., ALIAHMADI, A., GOHARI, A. R., MAROOFI, H., ARDALAN, A.. New coumarin derivatives from Ferula pseudalliacea with antibacterial activity. Natural product research, v. 30 , n. 24 , p. $2747-2753,2016$. DOI: https://doi.org/10.1080/14786419.2016.1149705

DE LEO, M., DE TOMMASI, N., SANOGO, R., D'ANGELO, V., GERMANÒ, M. P., BISIGNANO, G., BRACA, A.. Triterpenoid saponins from Pteleopsis suberosa stem bark.

Phytochemistry, v. 67, n. 24, p. 2623-2629, 2006. DOI: https://doi.org/10.1016/j.phytochem.2006.07.017

DE MONTE, C., BIZZARRI, B., GIDARO, M. C., CARRADORI, S., MOLLICA, A., LUISI, G., PARAPINI, S. (2015). Bioactive compounds of Crocus sativus $L$. and their semi-synthetic derivatives as promising anti-Helicobacter pylori, antimalarial and anti-leishmanial agents. Journal of enzyme inhibition and medicinal chemistry, 30(6), 1027-1033. DOI: https://doi.org/10.3109/14756366.2014.1001755

DE, R., KUNDU, P., SWARNAKAR, S., RAMAMURTHY, T., CHOWDHURY, A., NAIR, G. B., MUKHOPADHYAY, A. K.. Antimicrobial activity of curcumin against Helicobacter pylori isolates from India and during infections in mice.

Antimicrobial agents and chemotherapy, v. 53, n. 4, p. 1592-1597, 2009. DOI:

http://dx.doi.org/10.1128/AAC.01242-08

DO CARMO SOUZA, M., BESERRA, A. M. S., MARTINS, D. C., REAL, V. V., DOS SANTOS, R. A. N., RAO, V. S., DE OLIVEIRA MARTINS, D. T. (2009). In vitro and in vivo anti-Helicobacter pylori activity of Calophyllum brasiliense Camb. Journal of ethnopharmacology, 123(3), 452-458. DOI: https://doi.org/10.1016/j.jep.2009.03.030

EPIFANO, F., MENGHINI, L., PAGIOTTI, R., ANGELINI, P., GENOVESE, S., \& CURINI, M.. In vitro inhibitory activity of boropinic acid against Helicobacter pylori. Bioorganic \& medicinal chemistry letters, v. 16, n. 21, p. 5523-5525, 2006. DOI: https://doi.org/10.1016/j.bmcl.2006.08.043 
ESPINOSA-RIVERO, J., RENDÓN-HUERTA, E., \& ROMERO, I. (2015). Inhibition of Helicobacter pylori growth and its colonization factors by Parthenium hysterophorus extracts. Journal of ethnopharmacology, 174, 253-260. DOI: https://doi.org/10.1016/j.jep.2015.08.021

FABRY, W., OKEMO, P. O., \& ANSORG, R.. Antibacterial activity of East African medicinal plants. Journal of Ethnopharmacology, v. 60, n. 1, p. 79-84, 1998. DOI: https://doi.org/10.1016/S0378-8741(97)001281

FABRY, W., OKEMO, P., \& ANSORG, R. (1996). fungistatic and fungicidal activity of East African medicinal plants. Mycoses, 39(1-2), 67-70. DOI: https://doi.org/10.1111/j.14390507.1996.tb00087.x

FRANZ, GABRIELA MARIA.. Atividade biológica e composição química de méis produzidos em alguns Municípios da Amazônia, Cerrado e Pantanal de Mato Grosso. Dissertação (Mestrado em Ciências Ambientais) - Universidade do Estado de Mato Grosso (UNEMAT), Cáceres, 2015.

FUKAI, T., MARUMO, A., KAITOU, K., KANDA, T., TERADA, S., \& NOMURA, T.. Anti-Helicobacter pylori flavonoids from licorice extract. Life sciences, v. 71, n. 12, p. 1449-1463, 2002. DOI: https://doi.org/10.1016/S0024-3205(02)01864-7

FUNATOGAWA, K., HAYASHI, S., SHIMOMURA, H., YOSHIDA, T., HATANO, T., ITO, H., \& HIRAI, Y.. Antibacterial activity of hydrolyzable tannins derived from medicinal plants against Helicobacter pylori. Microbiology and immunology, v. 48, n. 4, p. 251-261, 2004. DOI: https://doi.org/10.1111/j.1348$\underline{0421.2004 . t b 03521 . x}$

GADHI, C. A., BENHARREF, A., JANA, M., \& LOZNIEWSKI, A.. Anti-Helicobacter pylori activity of Aristolochia paucinervis Pomel extracts. Journal of ethnopharmacology, v. 75, n. 2-3, p. 203-205, 2001. DOI: https://doi.org/10.1016/S03788741(01)00184-2

GERMANO, M. P., SANOGO, R., GUGLIELMO, M., DE PASQUALE, R., CRISAFI, G., \& BISIGNANO, G. (1998). Effects of Pteleopsis suberosa extracts on experimental gastric ulcers and Helicobacter pylori growth. Journal of ethnopharmacology, 59(3), 167-172. DOI: https://doi.org/10.1016/S0378-8741(97)00109-8

GOEL, R. K., SAIRAM, K., BABU, M. D., TAVARES, I. A., RAMAN, A. (2003). In vitro evaluation of Bacopa monniera on anti-Helicobacter pylori activity and accumulation of prostaglandins. Phytomedicine, 10(6-7), 523-527. https://doi.org/10.1078/094471103322331494

GOMES, ANGELA NELLY.. O novo consumidor de produtos naturais: Consumindo conceitos muito mais do que produtos. 2009.

GOMEZ-FLORES, R., ESPINOSA-RAMOS, D., QUINTANILLALICEA, R., BARRÓN-GONZALEZ, M. P., TAMEZ-GUERRA, P., TAMEZ-GUERRA, R., \& RODRIGUEZ-PADILLA, C. (2016). Antimicrobial activity of Gymnosperma glutinosum (Spreng.) less.(Asteraceae) methanol extracts against Helicobacter pylori. African Journal of Traditional, Complementary and Alternative Medicines, 13(4), 55-59. DOI: http://dx.doi.org/10.21010/aitcam.v13i4.9
GRAHAM, D. Y., ANDERSON, S. Y., \& LANG, T. (1999). Garlic or jalapeno peppers for treatment of Helicobacter pylori infection. The American journal of gastroenterology, 94(5), 1200. DOI: http://dx.doi.org/10.1111/j.15720241.1999.01066.x

HAMASAKI, N., ISHII, E., TOMINAGA, K., TEZUKA, Y., NAGAOKA, T., KADOTA, S., YANO, I.. Highly selective antibacterial activity of novel alkyl quinolone alkaloids from a Chinese herbal medicine, Gosyuyu (Wu-Chu-Yu), against Helicobacter pylori in vitro. Microbiology and immunology, v. 44, n. 1, p. 9-15, 2000.

HASHIMOTO, T., AGA, H., CHAEN, H., FUKUDA, S., \& KURIMOTO, M.. Isolation and identification of antiHelicobacter pylori compounds from Polygonum tinctorium Lour. Natural medicines v. 53, n. 1, p. 27-31, 1999. DOI: https://ci.nii.ac.jp/naid/110008731922

HOLETZ, F. B., PESSINI, G. L., SANCHES, N. R., CORTEZ, D. A. G., NAKAMURA, C. V., \& DIAS FILHO, B. P.. Screening of some plants used in the Brazilian folk medicine for the treatment of infectious diseases. Memórias do Instituto Oswaldo Cruz, v. 97, n. 7, p. 1027-1031, 2002. DOI: http://dx.doi.org/10.1590/S0074-02762002000700017

ILONA MUCSIE, J. M., MARUYAMA, S., \& SAKAGAMI, H. (2001).. Biological Activity of 3 Fruit Vegetable," Anastasia Green", 3 Species of Sweet Pepper. in vivo, 15, 437-442. DOI: https://doi.org/0258-851x/2001200+.40

INATSU, S., OHSAKI, A., \& NAGATA, K.. Idebenone acts against growth of Helicobacter pylori by inhibiting its respiration. Antimicrobial agents and chemotherapy, v. 50, n. 6 , p. 2237-2239, 2006. DOI: https://doi.org/10.1128/AAC.01118-05

KADOTA, S., BASNET, P., ISHII, E., TAMURA, T., \& NAMBA, T. Antibacterial activity of trichorabdal A from Rabdosia trichocarpa against Helicobacter pylori. Zentralblatt für Bakteriologie, v. 286, n. 1, p. 63-67, 1997. DOI: https://doi.org/10.1016/s0934-8840(97)80076

KIM, S., HONG, I., WOO, S., JANG, H., PAK, S., \& HAN, S.. Isolation of abscisic acid from Korean acacia honey with antiHelicobacter pylori activity. Pharmacognosy magazine, v. 13, n. Suppl 2, p. S170, 2017. DOI:

https://doi.org/10.4103/0973-1296.210166

KOLUNDŽIĆ, M., STANOJKOVIĆ, T., RADOVIĆ, J., TAČIĆ, A., DODEVSKA, M., MILENKOVIĆ, M., KUNDAKOVIĆ, T.. Cytotoxic and Antimicrobial Activities of Cantharellus cibarius Fr.(Cantarellaceae). Journal of medicinal food, v. 20, n. 8, p. 790-796, 2017. DOI: https://doi.org/10.1089/jmf.2016.0176

KONSTANTINOPOULOU, M., KARIOTI, A., SKALTSAS, S., \& SKALTSA, H.. Sesquiterpene Lactones from Anthemis a Itissima and Their Anti-Helicobacter pylori Activity. Journal of natural products, v. 66, n. 5, p. 699-702, 2003. DOI: https://doi.org/10.1021/up020472m

KOUITCHEU MABEKU, L. B., EYOUM BILLE, B., TCHOUANGUEU, T. F., NGUEPI, E., \& LEUNDJI, H. Treatment of Helicobacter pylori infected mice with Bryophyllum pinnatum, a medicinal plant with antioxidant and antimicrobial properties, reduces bacterial load. 
Pharmaceutical biology, v. 55, n. 1, p. 603-610, 2017. DOI: https://doi.org/10.1080/13880209.2016.1266668

KOUITCHEU MABEKU, L. B., EYOUM BILLE, B., TCHOUANGUEU, T. F., NGUEPI, E., \& LEUNDJI, H. (2017). Treatment of Helicobacter pylori infected mice with Bryophyllum pinnatum, a medicinal plant with antioxidant and antimicrobial properties, reduces bacterial load. Pharmaceutical biology, 55(1), 603-610. DOI: https://doi.org/10.1080/13880209.2016.1266668

KRIVOKUĆA, M., NIKETIĆ, M., MILENKOVIĆ, M., \& KUNDAKOVIĆ, T.. Anti-Helicobacter pylori Activity of Four Alchemilla Species (Rosaceae). Natural product communications, v. 10, n. 8, p. 1369-1371, 2015. DOI: https://www.researchgate.net/publication/283905159

KUBO, J., LEE, J. R., \& KUBO, I.. Anti-Helicobacter pylori agents from the cashew apple. Journal of Agricultural and Food Chemistry, v. 47, n. 2, p. 533-537, 1999. DOI: https://doi.org/10.1021/jf9808980

LEE, I. O., LEE, K. H., PYO, J. H., KIM, J. H., CHOI, Y. J., \& LEE, Y. C. (2007). Anti-inflammatory effect of capsaicin in Helicobacter pylori-infected gastric epithelial cells. Helicobacter, 12(5), 510-517. DOI: https://doi.org/10.1111/j.1523-5378.2007.00521.x

LEMOS, L. M., OLIVEIRA, R. B., SAMPAIO, B. L., CcanaCcapatinta, G. V., Da Costa, F. B., \& Martins, D. T. (2016). Brasiliensic and isobrasiliensic acids: isolation from Calophyllum brasiliense Cambess. and anti-Helicobacter pylori activity. Natural product research, 30(23), 2720-2725. DOI: https://doi.org/10.1080/14786419.2015.1137568

LI, Y., XU, C., ZHANG, Q., LIU, J. Y., \& TAN, R. X.. In vitro antiHelicobacter pylori action of 30 Chinese herbal medicines used to treat ulcer diseases. Journal of ethnopharmacology, v. 98 , n. 3, p. 329-333, 2005. DOI: https://doi.org/10.1016/j.jep.2005.01.020

LIU, J. H., LI, L., SHANG, X. D., ZHANG, J. L., \& TAN, Q.. AntiHelicobacter pylori activity of bioactive components isolated from Hericium erinaceus. Journal of ethnopharmacology, $v$. 183, p. 54-58, 2016. DOI:

https://doi.org/10.1016/j.jep.2015.09.004

MABE, K., YAMADA, M., OGUNI, I., \& TAKAHASHI, T.. In vitro and in vivo activities of tea catechins against Helicobacter pylori. Antimicrobial agents and chemotherapy, v. 43, n. 7, p. 1788-1791, 1999. DOI: https://doi.org/10390246

MAHADY, G. B., MATSUURA, H., \& PENDLAND, S. L.. Allixin, a phytoalexin from garlic, inhibits the growth of Helicobacter pylori in vitro. The American journal of gastroenterology, $\mathrm{v}$. 96, n. 12 , p. 3454,2001 . DOI:

https://doi.org/10.1111/i.1572-0241.2001.05351

MAHADY, G. B., PENDLAND, S. L., STOIA, A., \& CHADWICK, L. R.. In vitro susceptibility of Helicobacter pylori to isoquinoline alkaloids from Sanguinaria canadensis and Hydrastis canadensis. Phytotherapy Research, v. 17, n. 3, p. 217-221, 2003. DOI: https://doi.org/10.1002/ptr.1108

MALEKZADEH, F., EHSANIFAR, H., SHAHAMAT, M., LEVIN, M., \& COLWELL, R. R.. Antibacterial activity of black myrobalan (Terminalia chebula Retz) against Helicobacter pylori. International Journal of Antimicrobial Agents, v. 18 n. 1, p. 85-88, 2001. DOI: https://doi.org/10.1016/S09248579(01)00352-1

MALFERTHEINER, P., MEGRAUD, F., O'MORAIN, C. A., GISBERT, J. P., KUIPERS, E. J., AXON, A. T., HUNT, R.. Management of Helicobacter pylori infection-the Maastricht V/Florence consensus report. Gut, p. gutjnl-2016-312288, 2016. DOI: http://dx.doi.org/10.1136/gutjnl-2016-312288

MANYI-LOH, C. E., CLARKE, A. M., \& NDIP, R. N.. Detection of phytoconstituents in column fractions of $n$-hexane extract of Goldcrest honey exhibiting anti-Helicobacter pylori activity. Archives of medical research, v. 43, n. 3, p. 197-204, 2012. DOI: https://doi.org/10.1016/j.arcmed.2012.04.006

MANYI-LOH, C. E., CLARKE, A. M., GREEN, E., \& NDIP, R. N.. Inhibitory and bactericidal activity of selected South African honeys and their solvent extracts against clinical isolates of Helicobacter pylori. Pakistan Journal of Pharmaceutical Sciences, v. 26, n. 5, p. 897-906, 2013.

MARTINI, S., D'ADDARIO, C., COLACEVICH, A., FOCARDI, S., BORGHINI, F., SANTUCCI, A., ROSSI, C.. Antimicrobial activity against Helicobacter pylori strains and antioxidant properties of blackberry leaves (Rubus ulmifolius) and isolated compounds. International journal of antimicrobial agents, v. 34 , n. 1 , p. $50-59$, 2009. DOI:

https://doi.org/10.1016/i.ijantimicag.2009.01.010

MASADEH, M. M., Alkofahi, A. S., Alzoubi, K. H., Tumah, H. N., \& Bani-Hani, K. (2014). Anti-Helicobactor pylori activity of some Jordanian medicinal plants. Pharmaceutical biology, 52(5), 566-569. DOI: https://doi.org/10.3109/13880209.2013.853811

MCGOVERN, D. P., ABBAS, S. Z., VIVIAN, G., \& DALTON, H. R. (1999). Manuka honey against Helicobacter pylori. Journal of the Royal Society of Medicine, 92(8), 439-439.

MIGUEL, G., FALEIRO, L., CAVALEIRO, C., SALGUEIRO, L., \& CASANOVA, J. (2008). Susceptibility of Helicobacter pylori to essential oil of Dittrichia viscosa subsp. revoluta.

Phytotherapy research, 22(2), 259-263. DOI:

https://doi.org/10.1002/ptr.2284

MOHER, D., LIBERATI, A., TETZLAFF, J., ALTMAN, D. G., \& PRISMA GROUP.. Reprint-preferred reporting items for systematic reviews and meta-analyses: the PRISMA statement. Physical therapy, v. 89, n. 9, p. 873-880, 2009. DOI: https://doi.org/10.1093/pti/89.9.873

MOHTASHAMI, R., HUSEINI, H. F., HEYDARI, M., AMINI, M., SADEQHI, Z., GHAZNAVI, H., MEHRZADI, S. (2015). Efficacy and safety of honey based formulation of Nigella sativa seed oil in functional dyspepsia: A double blind randomized controlled clinical trial. Journal of ethnopharmacology, 175, 147-152. DOI: https://doi.org/10.1016/i.jep.2015.09.022

NARIMAN, F., EFTEKHAR, F., HABIBI, Z., \& FALSAFI, T. (2004). Anti-Helicobacter pylori activities of six Iranian plants. Helicobacter, 9(2), 146-151. DOI: https://doi.org/10.1111/j.1083-4389.2004.00211.x

NDIP, R. N., AJONGLEFAC, A. N., MBULLAH, S. M., TANIH, N. F., AKOACHERE, J. F. T. K., NDIP, L. M., EFANGE, S. M. N.. In vitro anti-Helicobacter pylori activity of Lycopodium 
cernuum (Linn) Pic. Serm. African Journal of Biotechnology, v. 7, n. 22, 2008. DOI: https://doi.org/10.5897/AJB08.595

NDIP, R. N., TAKANG, A. E., ECHAKACHI, C. M., MALONGUE, A., AKOACHERE, J. F., NDIP, L. M., \& LUMA, H. N.. In-vitro antimicrobial activity of selected honeys on clinical isolates of Helicobacter pylori. African health sciences, v. 7, n. 4, 2007.

NDIP, R. N., TARKANG, A. E. M., MBULLAH, S. M., LUMA, H. N., MALONGUE, A., NDIP, L. M.; EFANGE, S. M.. In vitro antiHelicobacter pylori activity of extracts of selected medicinal plants from North West Cameroon. Journal of Ethnopharmacology, v. 114, n. 3, p. 452-457, 2007. DOI: https://doi.org/10.1016/i.jep.2007.08.037

NETO, M. R., TINTINO, S. R., DA SILVA, A. R. P., DO SOCORRO COSTA, M., BOLIGON, A. A., MATIAS, E. F.; COUTINHO, H. D. $M$.. Seasonal variation of Brazilian red propolis: Antibacterial activity, synergistic effect and phytochemical screening. Food and Chemical Toxicology, v. 107, p. 572-580, 2017. DOI: https://doi.org/10.1016/i.fct.2017.03.052

NGAN, L. T. M., MOON, J. K., SHIBAMOTO, T., \& AHN, Y. J.. Growth-inhibiting, bactericidal, and urease inhibitory effects of Paeonia lactiflora root constituents and related compounds on antibiotic-susceptible and-resistant strains of Helicobacter pylori. Journal of agricultural and food chemistry, v. 60 , n. 36, p. 9062-9073, 2012. DOI: https://doi.org/10.1021/if3035034

NJUME, C., AFOLAYAN, A. J., GREEN, E., \& NDIP, R. N.. Volatile compounds in the stem bark of Sclerocarya birrea (Anacardiaceae) possess antimicrobial activity against drugresistant strains of Helicobacter pylori. International journal of antimicrobial agents, v. 38, n. 4, p. 319-324, 2011. DOI: https://doi.org/10.1016/j.ijantimicag.2011.05.002

NOSTRO, A., CELLINI, L., BARTOLOMEO, S. D., CAMPLI, E. D., GRANDE, R., CANNATELLI, M. A.; ALONZO, V.. Antibacterial effect of plant extracts against Helicobacter pylori. Phytotherapy Research, v. 19, n. 3, p. 198-202, 2005. DOI: https://doi.org/10.1002/ptr.1640

NOSTRO, A., CELLINI, L., BARTOLOMEO, S. D., CANNATELLI, M. A., CAMPLI, E. D., PROCOPIO, F.; ALONZO, V.. Effects of combining extracts (from propolis or Zingiber officinale) with clarithromycin on Helicobacter pylori. Phytotherapy Research, v. 20, n. 3, p. 187-190, 2006. DOI: https://doi.org/10.1002/ptr.1830

OHSAKI, A., TAKASHIMA, J., CHIBA, N., \& KAWAMURA, M. Microanalysis of a selective potent anti-Helicobacter pylori compound in a Brazilian medicinal plant, Myroxylon peruiferum and the activity of analogues. Bioorganic \& medicinal chemistry letters, v. 9, n. 8, p. 1109-1112, 1999. DOI: https://doi.org/10.1016/S0960-894X(99)00141-9

OKELEYE, B. I., BESSONG, P. O., \& NDIP, R. N.. Preliminary phytochemical screening and in vitro anti-Helicobacter pylori activity of extracts of the stem bark of Bridelia micrantha (Hochst., Baill., Euphorbiaceae). Molecules, v. 16, n. 8, p. 6193-6205, 2011. DOI:

https://doi.org/10.3390/molecules16086193

OLIVEIRA, D. M., MELO, F. G., BALOGUN, S. O., FLACH, A., DE SOUZA, E. C. A., DE SOUZA, G. P.; ROCHA, I. N. A. COSTA;
SILVA, L. I.; MARTINS, D. T. O.; ASCÊNCIO, S. D.. Antibacterial mode of action of the hydroethanolic extract of Leonotis nepetifolia (L.) R. Br. involves bacterial membrane perturbations. Journal of ethnopharmacology, v. 172, p. 356-363, 2015. DOI: https://doi.org/10.1016/j.jep.2015.06.027

OPEKUN, A. R., YEH, C. W., OPEKUN, J. L., \& GRAHAM, D. Y. (2005). In vivo tests of natural therapy, Tibetan yogurt or fresh broccoli, for Helicobacter pylori infection. Methods and findings in experimental and clinical pharmacology, 27(5), 327-330. DOI: https://doi.org/10.1358/mf.2005.27.5.896760

PARK, B. S., LEE, H. K., LEE, S. E., PIAO, X. L., TAKEOKA, G. R., WONG, R. Y., KIM, J. H. (2006). Antibacterial activity of Tabebuia impetiginosa Martius ex DC (Taheebo) against Helicobacter pylori. Journal of ethnopharmacology, 105(12), 255-262. DOI: https://doi.org/10.1016/j.jep.2005.11.005

PARK, D., SHIN, K., CHOI, Y., GUO, H., CHA, Y., KIM, S. H., CHOI, E. K. (2016). Antimicrobial activities of ethanol and butanol fractions of white rose petal extract. Regulatory Toxicology and Pharmacology, 76, 57-62. DOI: https://doi.org/10.1016/j.yrtph.2016.01.011

PARREIRA, P., SOARES, B. I., FREIRE, C. S., SILVESTRE, A. J., REIS, C. A., MARTINS, M. C. L., \& DUARTE, M. F.. Eucalyptus spp. outer bark extracts inhibit Helicobacter pylori growth: in vitro studies. Industrial Crops and Products, v. 105, p. 207214, 2017. DOI:

https://doi.org/10.1016/j.indcrop.2017.05.012

PAULO, L., OLEASTRO, M., GALLARDO, E., QUEIROZ, J. A., \& DOMINGUES, F.. Anti-Helicobacter pylori and urease inhibitory activities of resveratrol and red wine. Food Research International, v. 44, n. 4, p. 964-969, 2011. DOI: https://doi.org/10.1016/i.foodres.2011.02.017

PERERA, L. M. S., RUEDAS, D., \& GÓMEZ, B. C.. Gastric antiulcer effect of Rhizophora mangle L. Journal of Ethnopharmacology, v. 77, n. 1, p. 1-3, 2001. DOI: https://doi.org/10.1016/S0378-8741(01)00277-X

ROBLES-ZEPEDA, R. E., VELÁZQUEZ-CONTRERAS, C. A., GARIBAY-ESCOBAR, A., GÁLVEZ-RUIZ, J. C., RUIZ-BUSTOS, E. (2011). Antimicrobial activity of Northwestern Mexican plants against Helicobacter pylori. Journal of Medicinal Food, 14(10), 1280-1283. DOI: https://doi.org/10.1089/jmf.2010.0263

RONG, Q., XU, M., DONG, Q., ZHANG, Y., LI, Y., YE, G., ZHAO, L.. In vitro and in vivo bactericidal activity of Tinospora sagittata (Oliv.) Gagnep. var. craveniana (SY Hu) Lo and its main effective component, palmatine, against porcine Helicobacter pylori. BMC complementary and alternative medicine, v. 16, n. 1, p. 331, 2016. DOI: https://doi.org/10.1186/s12906-016-1310-y

RÜEGG, T., CALDERÓN, A. I., QUEIROZ, E. F., SOLÍS, P. N., MARSTON, A., RIVAS, F., GUPTA, M. P. (2006). 3-Farnesyl-2hydroxybenzoic acid is a new anti-Helicobacter pylori compound from Piper multiplinervium. Journal of ethnopharmacology, 103(3), 461-467, 2006. DOI: https://doi.org/10.1016/i.jep.2005.09.014 
SAFAK, B., CIFTCI, I. H., OZDEMIR, M., KIYILDI, N., CETINKAYA, Z., AKTEPE, O. C., ALTINDIS, M. (2009). In vitro anti-Helicobacter pylori activity of usnic acid. Phytotherapy research, 23(7), 955-957, 2009. DOI:

https://doi.org/10.1002/ptr.2690

SAHIN, H. (2016). Honey as an apitherapic product: its inhibitory effect on urease and xanthine oxidase. Journal of enzyme inhibition and medicinal chemistry, 31(3), 490-494. DOI: https://doi.org/10.3109/14756366.2015.1039532

SAKUNPAK, A.; PANICHAYUPAKARANANT, P.. Antibacterial activity of Thai edible plants against gastrointestinal pathogenic bacteria and isolation of a new broad spectrum antibacterial polyisoprenylated benzophenone, chamuangone. Food Chemistry, v. 130, n. 4, p. 826-831, 2012. DOI: https://doi.org/10.1016/i.foodchem.2011.07.088

SALIH, B. A., Abasiyanik, F. M. (2003). Does regular garlic intake affect the prevalence of Helicobacter pylori in asymptomatic subjects?. Saudi medical journal, 24(8), 842845. DOI: http://dx.doi.org/12939668

SARTORATTO, A., MACHADO, A. L. M., DELARMELINA, C., FIGUEIRA, G. M., DUARTE, M. C. T., \& REHDER, V. L. G. (2004). Composition and antimicrobial activity of essential oils from aromatic plants used in Brazil. Brazilian Journal of Microbiology, 35(4), 275-280. DOI: http://dx.doi.org/10.1590/S1517-83822004000300001

SHANG, X., TAN, Q., LIU, R., YU, K., LI, P., ZHAO, G. P. (2013). In vitro anti-Helicobacter pylori effects of medicinal mushroom extracts, with special emphasis on the Lion's Mane mushroom, Hericium erinaceus (higher Basidiomycetes). International journal of medicinal mushrooms, 15(2), 2013. DOI: http://dx.doi.org/10.1615/IntJMedMushr.v15.i2.50

SHIKOV, A. N., POZHARITSKAYA, O. N., MAKAROV, V. G., KVETNAYA, A. S. (2008). Antibacterial activity of Chamomilla recutita oil extract against Helicobacter pylori. Phytotherapy Research, 22(2), 252-253, 2008. DOI: https://doi.org/10.1002/ptr.2243

SIDAHMED, H. M. A., HASHIM, N. M., ABDULLA, M. A., ALI, H. M., MOHAN, S., ABDELWAHAB, S. I. VADIVELU, J. (2015). Antisecretory, gastroprotective, antioxidant and antihelicobcter pylori activity of zerumbone from Zingiber Zerumbet (L.) Smith. PloS one, 10(3), e0121060. DOI: https://doi.org/10.1371/journal.pone.0121060

SILVA, O., VIEGAS, S., DE MELLO-SAMPAYO, C., COSTA, M. J. P., SERRANO, R., CABRITA, J., GOMES, E. T. (2012). AntiHelicobacter pylori activity of Terminalia macroptera root. Fitoterapia, 83(5), 872-876. DOI: https://doi.org/10.1016/j.fitote.2012.03.019

STAMATIS, G., KYRIAZOPOULOS, P., GOLEGOU, S., BASAYIANNIS, A., SKALTSAS, S., \& SKALTSA, H. (2003). In vitro anti-Helicobacter pylori activity of Greek herbal medicines. Journal of Ethnopharmacology, 88(2-3), 175-179. DOI: https://doi.org/10.1016/S0378-8741(03)00217-4

STEGE, P. W., DAVICINO, R. C., VEGA, A. E., CASALI, Y. A., CORREA, S., \& MICALIZZI, B. (2006). Antimicrobial activity of aqueous extracts of Larrea divaricata Cav (jarilla) against
Helicobacter pylori. Phytomedicine, 13(9-10), 724-727. DOI: https://doi.org/10.1016/i.phymed.2005.06.008

SUK, K. T., BAIK, S. K., KIM, H. S., PARK, S. M., PAENG, K. J., UH, Y.HAM, Y. L. (2011). Antibacterial effects of the urushiol component in the sap of the lacquer tree (Rhus verniciflua Stokes) on Helicobacter pylori. Helicobacter, 16(6), 434-443. DOI: https://doi.org/10.1111/j.1523-5378.2011.00864

TABAK, M., ARMON, R., \& NEEMAN, I. (1999). Cinnamon extracts' inhibitory effect on Helicobacter pylori. Journal of ethnopharmacology, 67(3), 269-277. DOI: https://doi.org/10.1016/S0378-8741(99)00054-9

TAKASHIMA, J., CHIBA, N., YONEDA, K., \& OHSAKI, A. (2002). Derrisin, a New Rotenoid from Derris $m$ alaccensis Plain and Anti-Helicobacter ylori Activity of Its Related Constituents. Journal of natural products, 65(4), 611-613. DOI: https://doi.org/10.1021/np010126p

TAN, P. V., BODA, M., \& ETOA, F. X. (2010). In vitro and in vivo anti-Helicobacter/Campylobacter activity of the aqueous extract of Enantia chlorantha. Pharmaceutical biology, 48(3), 349-356. DOI: http://10.3109/13880200903150377

TEIXEIRA, T. F., DE SOUZA, I. K. F., \& ROCHA, R. D. R. (2017). Helicobacter pylori: infecção, diagnóstico laboratorial e tratamento. Percurso Acadêmico, 6(12), 481-504. DOI: http://dx.doi.org/10.5752/P.2236-0603.2016v6n12p481

USTÜN, O., OZÇELIK, B., AKYÖN, Y., ABBASOGLU, U., \& YESILADA, E. (2006). Flavonoids with anti-Helicobacter pylori activity from Cistus laurifolius leaves. Journal of ethnopharmacology, 108(3), 457-461. DOI: https://doi.org/10.1016/j.jep.2006.06.001

VIUDA-MARTOS, M., RUIZ-NAVAJAS, Y., FERNÁNDEZ-LÓPEZ, J., \& PÉREZ-ÁLVAREZ, J. A.. Functional properties of honey, propolis, and royal jelly. Journal of food science, v. 73, n. 9, 2008. DOI: https://doi.org/10.1111/j.17503841.2008.00966.x

VORAVUTHIKUNCHAI, S. P., \& MITCHELL, H.. Inhibitory and killing activities of medicinal plants against multiple antibiotic-resistant Helicobacter pylori. Journal of health science, v. 54, n. 1, p. 81-88, 2008. DOI: https://doi.org/10.1248/jhs.54.81

WANG, Y. C., \& HUANG, T. L.. Anti-Helicobacter pylori activity of Plumbago zeylanica L. Pathogens and Disease, v. 43, n. 3, p. 407-412, 2005. DOI: https://doi.org/10.1016/j.femsim.2004.10.015

WANG, Y. C., \& HUANG, T. L.. Screening of anti-Helicobacter pylori herbs deriving from Taiwanese folk medicinal plants. Pathogens and Disease, v. 43, n. 2, p. 295-300, 2005. DOI: https://doi.org/10.1016/j.femsim.2004.09.008

WANG, Y. C., LI, W. Y., WU, D. C., WANG, J. J., WU, C. H., LIAO, J. J., \& LIN, C. K.. In Vitro Activity of 2-methoxy-1, 4naphthoquinone and Stigmasta-7, 22-diene-3 $\beta$-ol from Impatiens balsamina L. against Multiple Antibiotic-Resistant Helicobacter pylori. Evidence-Based Complementary and Alternative Medicine, v. 2011, 2011. DOI: https://doi.org/10.1093/ecam/nep147 
WANG, YUAN-CHUEN.. Medicinal plant activity on Helicobacter pylori related diseases. World Journal of Gastroenterology: WJG, v. 20, n. 30, p. 10368, 2014. DOI: https://doi.org/10.3748/wjg.v20.i30.10368

WESELER, A., GEISS, H. K., SALLER, R., \& REICHLING, J. (2005). A novel colorimetric broth microdilution method to determine the minimum inhibitory concentration (MIC) of antibiotics and essential oils against Helicobacter pylori. Die Pharmazie-An International Journal of Pharmaceutical Sciences, 60(7), 498-502.

WHO.. Organização Mundial de Saúde. Traditional medicine: definitions. 2008.

YE, H., LIU, Y., LI, N., YU, J., CHENG, H., LI, J., \& ZHANG, X. Z.. Anti-Helicobacter pylori activities of Chenopodium ambrosioides $\mathrm{L}$. in vitro and in vivo. World Journal of Gastroenterology: WJG, v. 21, n. 14, p. 4178, 2015. DOI: https://doi.org/10.3748/wjg.v21.i14.4178

YEE, Y. K., \& KOO, M. W. L.. Anti-Helicobacter pylori activity of Chinese tea: in vitro study. Alimentary pharmacology \& therapeutics, v. 14, n. 5, p. 635-638, 2000. DOI: https://doi.org/10.1046/j.1365-2036.2000.00747.x

YEŞILADA, E., GÜRBÜZ, I., \& SHIBATA, H.. Screening of Turkish anti-ulcerogenic folk remedies for anti-Helicobacter pylori activity. Journal of Ethnopharmacology, v. 66, n. 3, p. 289-293, 1999. DOI: https://doi.org/10.1016/S03788741(98)00219-0

YIN, S., FAN, C. Q., DONG, L., \& YUE, J. M.. Psoracorylifols A$E$, five novel compounds with activity against Helicobacter pylori from seeds of Psoralea corylifolia. Tetrahedron, v. 62, n. 11 , p. $2569-2575,2006$. DOI:

https://doi.org/10.1016/i.tet.2005.12.041

YU, X. D.; XIE, J. H.; WANG, Y. H.; LI, Y. C.; MO, Z. Z.; ZHENG, Y. F.; SU, J. Y.; LIANG, Y.E.; HUANG, P.. Selective antibacterial activity of patchouli alcohol against Helicobacter pylori based on inhibition of urease. Phytotherapy research, v. 29, n. 1, p. 67-72, 2015. DOI: https://doi.org/10.1002/ptr.5227

ZAIDI, S. F. H., YAMAMOTO, T., REFAAT, A., AHMED, K., SAKURAI, H., SAIKI, I., KONDO, T.; USMANGHANI, K.; KADOWAKI, M.; SUGIYAMA, T.. Modulation of ActivationInduced Cytidine Deaminase by Curcumin in Helicobacter pylori-Infected Gastric Epithelial Cells. Helicobacter, v. 14, n. 6, p. 588-595, 2009. DOI: https://doi.org/10.1111/j.15235378.2009.00724

ZAIDI, S. F. H.; YAMADA, K.; KADOWAKI, M.; USMANGHANI, K.; SUGIYAMA, T.. Bactericidal activity of medicinal plants, employed for the treatment of gastrointestinal ailments, against Helicobacter pylori. Journal of Ethnopharmacology, v. 121 , n. 2 , p. $286-291,2009$. DOI: https://doi.org/10.1016/j.jep.2008.11.001

ZHANG, B. B., DAI, Y., LIAO, Z. X., \& DING, L. S.. Three new antibacterial active diarylheptanoids from Alpinia officinarum. Fitoterapia, v. 81, n. 7, p. 948-952, 2010. DOI: https://doi.org/10.1016/j.fitote.2010.06.015

ZHANG, X. Q.; GU, H. M.; LI, X. Z.; XU, Z. N.; CHEN, Y. S.; \& LI, $Y$.. Anti-Helicobacter pylori compounds from the ethanol extracts of Geranium wilfordii. Journal of ethnopharmacology, v. 147, n. 1, p. 204-207, 2013. DOI: https://doi.org/10.1016/j.jep.2013.02.032

A CBPC - Companhia Brasileira de Produção Científica (CNPJ: 11.221.422/0001-03) detém os direitos materiais desta publicação. Os direitos referem-se à publicação do trabalho em qualquer parte do mundo, incluindo os direitos às renovações, expansões e disseminações da contribuição, bem como outros direitos subsidiários. Todos os trabalhos publicados eletronicamente poderão posteriormente ser publicados em coletâneas impressas sob coordenação da Sustenere Publishing, da Companhia Brasileira de Produção Científica e seus parceiros autorizados. Os (as) autores (as) preservam os direitos autorais, mas não têm permissão para a publicação da contribuição em outro meio, impresso ou digital, em português ou em tradução. 